\title{
Serum Extracellular Vesicles Contain Protein Biomarkers for Primary Sclerosing Cholangitis and Cholangiocarcinoma
}

\author{
Ander Arbelaiz, ${ }^{1}$ Mikel Azkargorta, ${ }^{2,3}$ Marcin Krawczyk, ${ }^{4,5}$ Alvaro Santos-Laso, ${ }^{1}$ Ainhoa Lapitz, ${ }^{1}$ Maria J. Perugorria, ${ }^{1,3,6}$ \\ Oihane Erice, ${ }^{1}$ Esperanza Gonzalez, ${ }^{7}$ Raul Jimenez-Agüero, ${ }^{1}$ Adelaida Lacasta, ${ }^{1}$ Cesar Ibarra, ${ }^{8}$ Alberto Sanchez-Campos, ${ }^{8}$ \\ Juan P. Jimeno, ${ }^{9}$ Frank Lammert, ${ }^{4}$ Piotr Milkiewicz, ${ }^{10,11}$ Marco Marzioni, ${ }^{12}$ Rocio I.R. Macias, ${ }^{3,13}$ Jose J.G. Marin, ${ }^{3,13}$ \\ Tushar Patel, ${ }^{14}$ Gregory J. Gores, ${ }^{15}$ Ibon Martinez, ${ }^{16}$ Félix Elortza, ${ }^{2,3}$ Juan M. Falcon-Perez, ${ }^{3,6,7}$ \\ Luis Bujanda, ${ }^{1,3}$ and Jesus M. Banales ${ }^{1,3,6}$
}

\begin{abstract}
Cholangiocarcinoma (CCA) includes a heterogeneous group of biliary cancers with poor prognosis. Several conditions, such as primary sclerosing cholangitis (PSC), are risk factors. Noninvasive differential diagnosis between intrahepatic CCA and hepatocellular carcinoma (HCC) is sometimes difficult. Accurate noninvasive biomarkers for PSC, CCA, and HCC are not available. In the search for novel biomarkers, serum extracellular vesicles $(\mathrm{EV})$ were isolated from CCA ( $\mathrm{n}=43)$, PSC $(\mathrm{n}=30)$, or HCC ( $\mathrm{n}=29$ ) patients and healthy individuals (control, $\mathrm{n}=32$ ); and their protein content was characterized. By using nanoparticle tracking analysis, serum EV concentration was found to be higher in HCC than in all the other groups. Round morphology (by transmission electron microscopy), size ( $\sim 180 \mathrm{~nm}$ diameter by nanoparticle tracking analysis), and markers (clusters of differentiation 9, 63, and 81 by immunoblot) indicated that most serum EV were exosomes. Proteome profiles (by mass spectrometry) revealed multiple differentially expressed proteins among groups. Several of these proteins showed high diagnostic values with maximum area under the receiver operating characteristic curve of 0.878 for CCA versus control, 0.905 for CCA stage I-II versus control, 0.789 for PSC versus control, 0.806 for noncirhottic PSC versus control, 0.796 for CCA versus PSC, 0.956 for CCA stage I-II versus PSC, 0.904 for HCC versus control, and 0.894 for intrahepatic CCA versus HCC. Proteomic analysis of $\mathrm{EV}$ derived from CCA human cells in vitro revealed higher abundance of oncogenic proteins compared to EV released by normal human cholangiocytes. Orthotopic implant of CCA human cells in the liver of immunodeficient mice resulted in the release to serum of EV containing some similar human oncogenic proteins. Conclusion: Proteomic signatures found in serum EV of CCA, PSC, and HCC patients show potential usefulness as diagnostic tools. (HEPATOLOGy 2017;66:1125-1143).
\end{abstract}

\section{SEE EDITORIAL ON PAGE 1029}

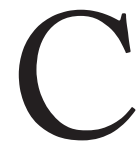

holangiocarcinomas (CCAs) are heterogeneous malignant tumors with dismal prognosis. Their incidence is increasing worldwide, CCAs represent the second most frequent primary liver tumor and $\sim 3 \%$ of all gastrointestinal cancers. ${ }^{(1,2)}$
The etiology remains largely unknown, but several conditions such as primary sclerosing cholangitis (PSC) increase the odds ( 5\%-15\%) of developing CCA. ${ }^{(3)}$ Late diagnosis due to the lack of early symptoms as well as the refractory nature of these tumors seriously compromise the therapeutic options and patient outcome. ${ }^{(1,2)}$ CCAs are commonly diagnosed

Abbreviations: A1AG1, alpha-1-acid glycoprotein 1; AFP, alpha-fetoprotein; AMPN, aminopeptidase $N$; AUC, area under the receiver operating characteristic curve; CA19-9, carbohydrate antigen 19-9; CCA, cholangiocarcinoma; CD, cluster of differentiation; CRP, C-reactive protein; EGFR, epidermal growth factor receptor; EV, extracellular vesicles; FIBG, fibrinogen gamma chain; FCN1/FCN2, ficolins 1 and 2, respectively; GO, gene ontology; H69, SV40-immortalized human cholangiocyte; HCC, hepatocellular carcinoma; IPA, Ingenuity Pathway Analysis; ITGB4, integrin beta-4; LG3BP, galectin-3-binding protein; MRI, magnetic resonance imaging; MUC1, mucin-1; NHC, normal human cholangiocytes; NTA, nanoparticle tracking analysis; PIGR, polymeric immunoglobulin receptor; PSC, primary sclerosing cholangitis; TEM, transmission electron microscopy; VNN1, pantetheinase; WCE, whole-cell extract. 
in advanced stages, when the disease is disseminated, by combining imaging methods (i.e., computed tomography, magnetic resonance imaging [MRI], or endoscopic retrograde cholangiopancreatography), nonspecific tumor biomarkers in serum (i.e., carbohydrate antigen 19-9 [CA19-9] and carcinoembryonic antigen), and histological analysis of tumor biopsies. ${ }^{(3)}$ On the other hand, PSC is commonly diagnosed by magnetic resonance cholangiography and by histological analysis of biopsies. ${ }^{(4-6)}$ To date, there is a lack of accurate noninvasive methods for the diagnosis of both PSC and CCA, as well as for the differential diagnosis between PSC versus CCA and intrahepatic CCA versus hepatocellular carcinoma (HCC). ${ }^{(1,3)}$

In recent years, extracellular vesicles $(\mathrm{EV})$ have emerged as an important tool in the search for biomarkers of different disorders as well as pathogenic players involved in disease development and progression. EV are lipid bilayer spheres of 40 to $>1,000 \mathrm{~nm}$ in diameter generated by diverse cell types and contain specific proteins, lipids, RNA species, DNA, and metabolites. ${ }^{(7,8)}$ These small vesicles, which are released to the extracellular media and are present in many biological fluids, participate in intercellular communication in both physiological and pathological conditions. ${ }^{(7-11)}$ To date, the most studied EV are exosomes, which are small vesicles $(\sim 40-300 \mathrm{~nm}$ diameter) formed in multivesicular bodies upon invagination of the late endosome membrane. EV are present in different biological fluids such as blood, urine, saliva, bile, and ascites; and among their components they carry biomarkers for several diseases and play important roles in human pathophysiology. ${ }^{(7-11)}$

In the present study, we have characterized the serum EV of CCA, PSC, HCC patients, and healthy individuals, as well as the EV derived from CCA human cell lines and normal human cholangiocytes (NHC) in vitro. The protein content of $\mathrm{EV}$ was

Supported by the Spanish Ministries of Economy and Competitiveness (FIS PI12/00380, FIS PI15/01132, and Miguel Servet Program CON14/ 00129, to J.M.B.; FIS PI14/00399, to M.J.P.; PI12-01604 and SAF2015-66312-R, to J.M.F-P.; FIS PI16/00598 and SAF2013-40620-R, to J.J.G.M.; SAF2016-75197-R, to R.I.R.M.), cofinanced by Fondo Europeo de Desarrollo Regional; Instituto de Salud Carlos III (CIBERehd) (EHD15PI05, to J.M.B., R.I.R.M., L.B., and J.J.G.M.); Junta de Castilla y Leon (SA015U13 and BIO/SA52/15, to J.J.G.M.); Diputación Foral Gipuzkoa (DFG14/007, to L.B.; DFG15/010 and DFG16/004, to J.M.B.); Departments of Industry, Tourism, Trade and Health of the Basque Country (2013111173, to L.B.; 2012111086 Etortek, to J.M.F-P.); Basque Foundation for Innovation and Health Research: EiTB Maratoia (BIO15/CA/O16/ BD, to J.M.B.); German Federal Ministry of Education and Research (core grant Liver Systems Medicine LiSyM 031L005, to F.L.); and Asociación Espaola Contra el Cancer (to J.M.B. and O.E.) and the Basque government (to A.S.-L.).

Copyright $\odot 2017$ by the American Association for the Study of Liver Diseases.

View this article online at wileyonlinelibrary.com.

DOI 10.1002/hep.29291

Potential conflict of interest: Nothing to report.

\section{ARTICLE INFORMATION:}

From the ${ }^{1}$ Department of Liver and Gastrointestinal Diseases, Biodonostia Research Institute, Donostia University Hospital, University of the Basque Country (UPV/EHU), San Sebastian, Spain; ${ }^{2}$ Proteomics Platform, CIC bioGUNE, CIBERehd, ProteoRed-ISCIII, Bizkaia Science and Technology Park, Derio, Spain; ${ }^{3}$ National Institute for the Study of Liver and Gastrointestinal Diseases (CIBERehd), Carlos III National Institute of Health, Madrid, Spain; ${ }^{4}$ Department of Medicine II, Saarland University Medical Center, Saarland University, Homburg, Germany; ${ }^{5}$ Laboratory of Metabolic Liver Diseases, Department of General, Transplant and Liver Surgery, Medical University of Warsaw, Warsaw, Poland; ${ }^{6}$ IKERBASQUE, Basque Foundation for Science, Bilbao, Spain; ${ }^{7}$ Metabolomics Unit, CIC bioGUNE, CIBERehd, Derio, Spain; ${ }^{8}$ Hospital of Cruces, Bilbao, Spain; ${ }^{9}$ Complejo Hospitalario de Navarra, Pamplona, Spain; ${ }^{10}$ Liver and Internal Medicine Unit, Department of General, Transplant and Liver Surgery, Medical University of Warsaw, Warsaw, Poland; ${ }^{11}$ Translational Medicine Group, Pomeranian Medical University in Szczecin, Szczecin, Poland; ${ }^{12}$ Department of Gastroenterology, Università Politecnica delle Marche, Ancona, Italy; ${ }^{13}$ Experimental Hepatology and Drug Targeting (HEVEFARM), Biomedical Research Institute of Salamanca (IBSAL), University of Salamanca, Salamanca, Spain; ${ }^{14}$ Department of Cancer Biology, Mayo Clinic, Jacksonville, FL; ${ }^{15}$ Division of Gastroenterology and Hepatology, Mayo Clinic, Rochester, MN; ${ }^{16}$ OWL Metabolomics, Derio, Spain.

\section{ADDRESS CORRESPONDENCE AND REPRINT REQUESTS TO:}

Jesus M. Banales, Ph.D.

Department of Liver and Gastrointestinal Diseases, Biodonostia Health

Research Institute

Donostia University Hospital
Paseo del Dr. Begiristain s/n, E-20014

San Sebastian, Spain

E-mail: jesus.banales@biodonostia.org

Tel: +34-943006067 
determined, and the presence of novel biomarkers for PSC, CCA, and HCC, as well as oncogenes that might be involved in CCA tumor growth and dissemination, were investigated.

\section{Patients and Methods}

\section{PATIENTS}

Serum samples of CCA ( $\mathrm{n}=43)$, PSC $(\mathrm{n}=30)$, $\operatorname{HCC}(\mathrm{n}=29)$, and healthy $(\mathrm{n}=32)$ individuals were obtained from Donostia University Hospital (San Sebastian, Spain), Cruces University Hospital (Bilbao, Spain), "Complejo Hospitalario de Navarra" (Pamplona, Spain), and Medical University Hospital of Warsaw (Warsaw, Poland). Research protocols were approved by the ethical committees for clinical research of supporting institutions, and all patients signed written consent for the use of their samples for biomedical research. Supporting Table S1 summarizes the patients' characteristics. PSC patients were diagnosed by the presence of bile duct alterations including strictures or irregularities of intrahepatic or extrahepatic bile ducts using magnetic resonance cholangiography after excluding secondary causes of cholangitis. All patients fulfilled the criteria for the diagnosis of PSC according to the European Association for the Study of the Liver guidelines. ${ }^{(12)}$ CCA and HCC were diagnosed by histological analysis of tumor samples and/or by a combination of clinical, biochemical, and radiological approaches; and the tumor stage was determined according to the seventh edition of the American Joint Committee on Cancer classification. $^{(13)}$

\section{ORTHOTOPIC MOUSE MODEL OF CCA}

Human CCA cells (i.e., EGI1, $\mathrm{n}=500,000$ ) were injected subcutaneously in 8-week-old Crl:CD1Foxn $1^{n u}$ mice (Charles River) and allowed to grow for 1 month. Resultant tumors were removed, cut into small pieces $(\sim 0.25 \mathrm{~cm})$, and implanted in the livers of another group of 8-week-old immunodeficient mice (n $=16$ ). A control group with sham operated mice was included $(\mathrm{n}=14)$. Tumor implantation and growth within the liver were monitored by MRI at the initial time point and 1 and 2 months later. Blood samples for $\mathrm{EV}$ isolation were collected 1 week, 1 month, and 2 months after orthotopic tumor implantation. The research protocol was approved by the Ethical
Committee for Animal Research of the Biodonostia Health Research Institute (San Sebastian, Spain).

\section{CELL CULTURES}

NHC were isolated from normal liver tissue and characterized as described. ${ }^{(14-16)}$ In addition, nontumor SV40-immortalized human cholangiocytes (i.e., H69; a gift from Dr. D. Jefferson, Tufts University, Boston, MA) and two commercial human CCA cell lines (i.e., EGI1 and TFK1; Leibniz Institute DSMZGerman Collection of Microorganism and Cell Cultures, Germany) were used. All cells were tested as mycoplasma-negative during the experiments.

\section{ISOLATION OF EV FROM SERUM AND CELL CULTURES}

The protocol for the isolation of $\mathrm{EV}$ from blood or cell culture media is described in the Supporting Information and summarized in Supporting Fig. S1.

\section{TRANSMISSION ELECTRON MICROSCOPY}

For cryo-electron microscopy, EV samples were directly adsorbed onto glow-discharged holey carbon grids (QUANTIFOIL, Germany). Grids were blotted at $95 \%$ humidity and rapidly plunged into liquid ethane with the aid of VITROBOT (Maastricht Instruments BV, The Netherlands). Transmission electron microscope (TEM) images were obtained from vitrified samples at liquid nitrogen temperature using a JEM-2200FS/CR transmission cryo-electron microscope (JEOL, Japan) equipped with a field emission gun and operated at an acceleration voltage of $200 \mathrm{kV}$.

\section{EV SIZE AND CONCENTRATION}

The size distribution and concentration of EV were calculated by nanoparticle tracking analysis (NTA) using a NanoSight LM10 system (Malvern, UK) equipped with a fast video capture and particletracking software. NTA postacquisition settings were kept constant for all samples. Each video was analyzed to obtain the mode vesicle size and the concentration.

\section{IMMUNOFLUORESCENCE}

The expression of the exosome marker cluster of differentiation 63 (CD63) was determined in NHC, 
H69, and CCA (i.e., EGI1 and TFK1) cells by immunofluorescence as described in Supporting Information. ${ }^{(16)}$

\section{IMMUNOBLOTTING}

Protein expression was analyzed as described in Supporting Information and using the antibodies listed in Supporting Table S2.

\section{MASS SPECTROMETRY}

Proteomic analysis of EV was performed simultaneously by using nanoscale chromatography coupled online to two different types of mass spectrometry (i.e., Orbitrap-XL [Thermo] and Synapt G2S [Waters]). Proteins were identified according to the Uniprot/ Swissprot human database. Progenesis LC-MS (version 4.0.4265.42984, Nonlinear Dynamics) was used for label-free differential protein expression analysis. Functional analysis of proteins was determined by gene ontology (GO) enrichment using the DAVID online tool (http://david.abcc.ncifcrf.gov/summary.jsp). Ingenuity Pathway Analysis (IPA) was used to determine the potential functional interaction between the proteins identified. All the information is detailed in Supporting Information.

\section{STATISTICAL ANALYSIS}

Results were statistically analyzed using GraphPad Prism 6 statistical software (San Diego, CA). Data are shown as mean \pm standard error of the mean. For comparisons between two groups, parametric Student $t$ test or nonparametric Mann-Whitney test was used. For comparisons between more than two groups, the nonparametric Kruskal-Wallis test followed by a posteriori Dunn's test or the parametric one-way analysis of variance test followed by a posteriori Tukey's post hoc test was used. Serum concentrations of tested biomarkers with the best predictive value to discriminate between patients with CCA, PSC or HCC and controls were determined using area under the receiver operating characteristic curve (AUC) analysis with SPSS 20.0 software (IBM, Ehningen, Germany) followed by calculations of sensitivity and specificity. Expression differences and $P$ values of the biomarker proteins were calculated using logarithmic values as samples did not follow a gaussian distribution. Differences were considered significant when $P<0.05$.

\section{Results}

\section{CHARACTERIZATION OF SERUM EV FROM CCA, PSC, HCC, AND HEALTHY INDIVIDUALS}

Serum EV were characterized by TEM, immunoblotting, and NTA. These nanovesicles showed the typical exosome-like round morphology by TEM (Fig. 1A) and high concentrations of the exosome protein markers CD9, CD63, and CD81 by immunoblot compared to the whole-cell extract (WCE) of NHC (Fig. 1B). On the other hand, no expression of the endoplasmic reticulum $78-\mathrm{kDa}$ glucose-regulated protein (negative control) was found in the isolated serum $\mathrm{EV}$ compared to the high expression observed in the WCE of NHC, supporting the accuracy of the EV isolation approach. Analysis of the serum EV size (mode) by NTA revealed a slight decrease in the EV mode size in CCA versus PSC patients, although no differences were observed between the other groups. The average mode size of serum EV was $\sim 180 \mathrm{~nm}$ in all groups (Fig. 1C). Regarding the serum EV concentration, no differences were found between CCA or PSC patients and healthy controls, whereas HCC patients showed a slight increase in serum EV concentration compared to the other three groups (Fig. 1C).

\section{COMPARATIVE PROTEOME CONTENT OF SERUM EV FROM CCA, PSC, HCC, AND HEALTHY INDIVIDUALS}

The protein composition of serum EV isolated from CCA, PSC, and HCC patients and healthy individuals was determined using mass spectrometry technology. In agreement with previous results obtained by immunoblotting, the exosome markers CD9, CD63, CD81, and Flotillin-1 were identified in the serum EV isolated from all four experimental groups (Supporting Table S3). A total of 541 proteins were identified in serum EV of healthy controls compared to 427, 574, and 399 proteins found in PSC, CCA, and HCC patients, respectively (Fig. 1D). Then, the differential proteome content of serum EV from the CCA, PSC, HCC, and healthy control groups was determined. A total of 95 proteins were found differentially expressed in CCA versus controls, 161 in PSC versus controls, 50 in CCA versus PSC, and 98 in HCC versus controls. GO analysis revealed that the differential 
proteins in CCA versus control, PSC versus control, CCA versus PSC, and $\mathrm{HCC}$ versus control are related mostly to response to wounding, defense to infections, inflammatory responses, and immune activation (Fig. 1D). The selection of biomarkers between CCA versus control indicated that aminopeptidase N (AMPN), pantetheinase (VNN1), and polymeric immunoglobulin receptor (PIGR) show the best diagnostic capacity, with AUC values of $0.878,0.876$, and 0.844 , respectively. These results are in line with the AUC of CA19-9 (i.e., 0.907), a nonspecific serum tumor biomarker commonly employed in the diagnostic process of CCA (Fig. 2A). In serum EV from PSC patients, AMPN, ficolin-1 (FCN1), and neprilysin present the best diagnostic capacity, with AUC values of 0.789 , 0.771 , and 0.761 , respectively, compared to the healthy control group (Fig 2B). Since PSC is a major risk factor for CCA development, the differential diagnostic value of serum EV proteins was compared between CCA and PSC. A selection of 10 overexpressed proteins in CCA versus PSC patients presenting the best differential diagnostic values was carried out (Fig. 2C). In particular, fibrinogen gamma chain (FIBG), alpha1-acid glycoprotein 1 (A1AG1), and S100A8 proteins showed the best differential diagnostic capacity, with AUC values of $0.796,0.794$, and 0.759 , respectively (Fig. 2C). According to these data, the diagnostic capacity of FIBG, A1AG1, and S100A8 is in line with
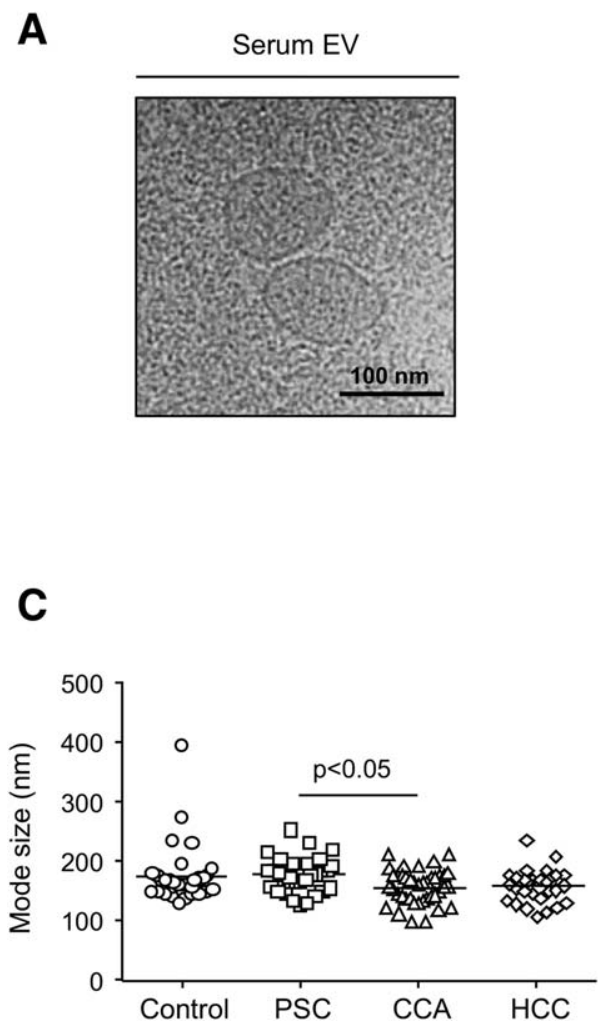
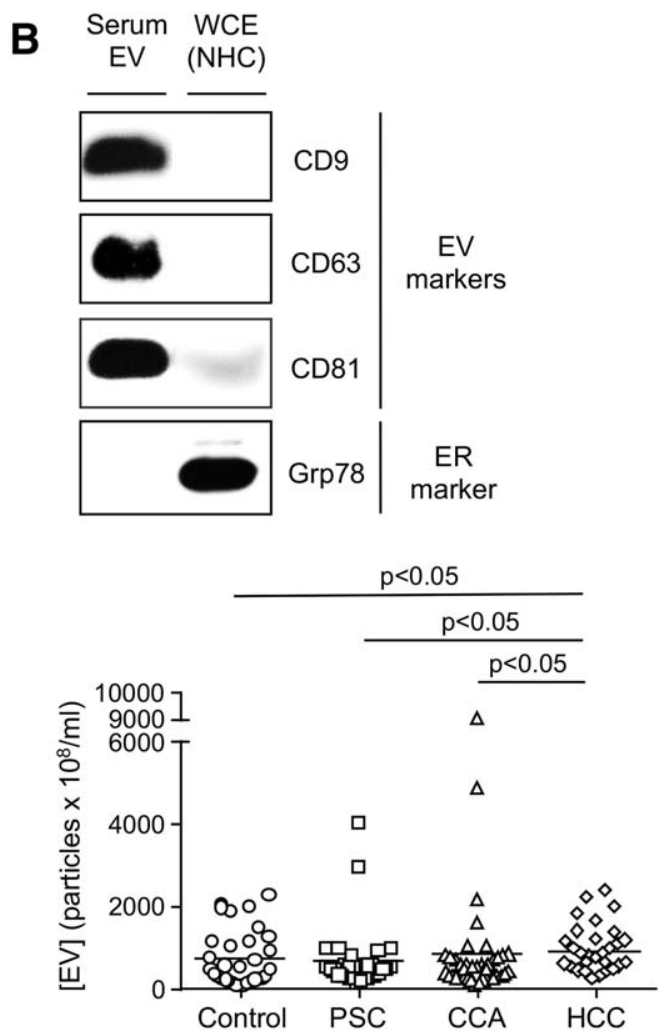

FIG. 1. Comparative analysis of serum EV from CCA, PSC, and HCC patients and healthy individuals. The protocol for isolating serum EV was validated in blood serum from healthy individuals. (A) TEM image of blood serum EV of healthy individuals showing the typical exosome-round size $(\sim 150 \mathrm{~nm})$ and morphology. (B) Representative immunoblots indicating that the EV isolated from blood serum of healthy individuals present enrichment of the EV markers CD9, CD63, and CD81 (positive controls) but do not contain the endoplasmic reticulum marker $78-\mathrm{kDa}$ glucose-regulated protein (negative control) compared to WCE of NHC used as control. (C) NTA of serum EV revealing a similar EV mode $(\sim 180 \mathrm{~nm})$ between CCA $(\mathrm{n}=41)$, PSC $(\mathrm{n}=30)$, HCC ( $=29)$, and healthy individuals (control) $(\mathrm{n}=32)$. An increased concentration of serum EV was found in HCC compared to the other three groups by NTA. (D) Venn diagrams showing the number of proteins identified for each comparison and total proteins identified in each case (two peptides, false discovery rate $<1 \%$ protein). GO (DAVID bioinformatics database) analysis of the proteins differentially present in serum EV from CCA versus PSC patients and CCA, PSC, or HCC patients versus healthy controls. Abbreviations: ER, endoplasmic reticulum; Grp78, 78-kDa glucose-regulated protein. 
CA19-9 (AUC, 0.819). However, of note, several of the best biomarker candidates for the differential diagnosis of CCA versus PSC improved their diagnostic values when comparing early-stage CCA (I-II) versus PSC (Fig. 2D). In particular, FCN2, inter-alphatrypsin inhibitor heavy chain $\mathrm{H} 4$, and FIBG showed higher diagnostic value (AUC, 0.956, 0.881, and 0.881, respectively) than CA19-9 (AUC, 0.736) in CCA I-II versus PSC patients (Fig. 2D). New biomarker candidates for $\mathrm{HCC}$ versus control were also found, especially galectin-3-binding protein (LG3BP) and PIGR, with AUC values (i.e., 0.904 and 0.837, respectively) higher than alpha-fetoprotein (AFP; AUC, 0.802) (Fig. 2D), a nonspecific serum tumor biomarker commonly employed in the diagnostic process of HCC.

Moreover, protein levels of VNN1, C-reactive protein (CRP), FIBG, IGHA1, A1AG1, and gammaglutamyltransferase 1 are increased in serum EV of CCA patients compared to all PSC, HCC, or healthy

\section{D}
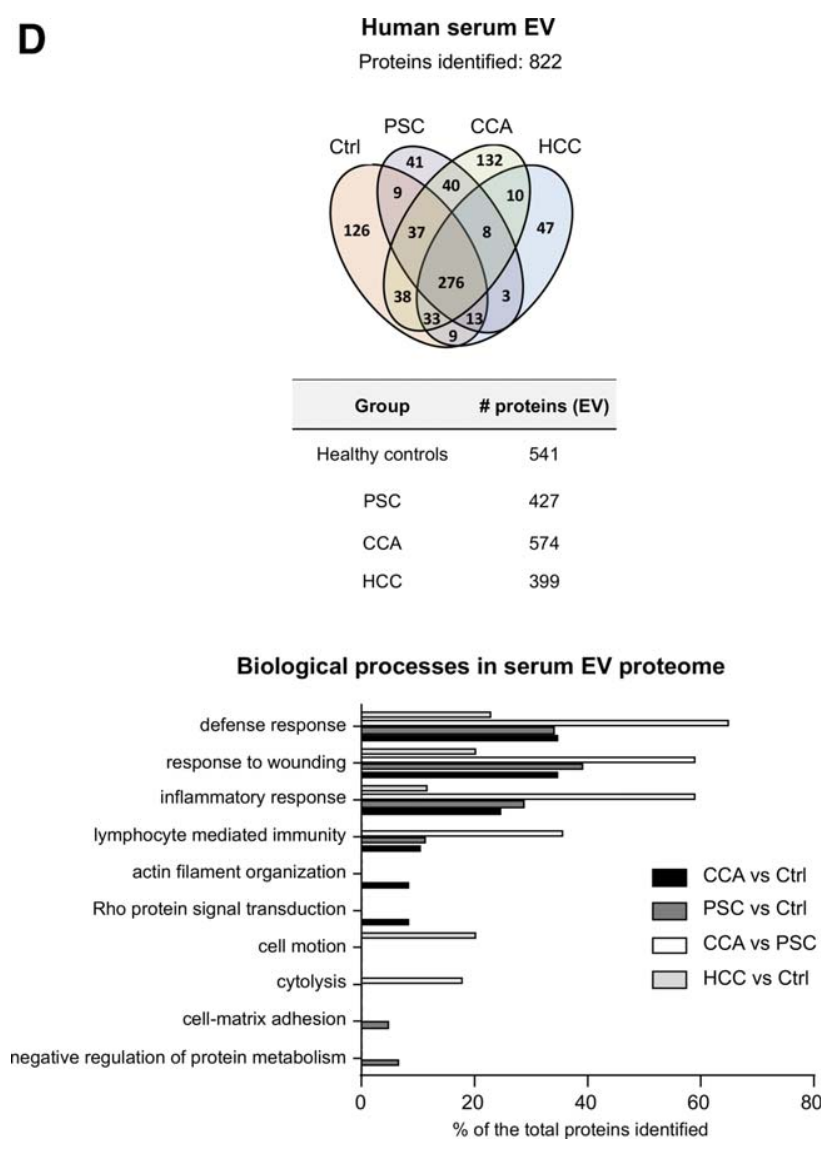

FIG. 1. (Continued). individuals (Fig. 2E). Protein levels of FCN2 in serum $\mathrm{EV}$ are decreased in PSC patients versus both control individuals and CCA patients (Supporting Fig. S2). Moreover, both AMPN and neprilysin levels are elevated in CCA and PSC patients compared to healthy controls and HCC patients (Fig. 2E; Supporting Fig. S2). On the other hand, PIGR, which is elevated in all PSC, CCA, and HCC patients compared to healthy controls, seems to be a nonspecific biomarker probably related to inflammation (Fig. 2E). Finally, LG3BP is increased in HCC compared to all CCA and PSC patients and healthy controls (Fig. 2E).

Next, immunoblot experiments comparing the expression of different identified biomarkers (e.g., PIGR, AMPN, and CRP) in serum EV, serum protein pellet, serum without $\mathrm{EV}$, and total serum of all normal, PSC, and CCA individuals were performed. Our data indicate that PIGR and AMPN are mostly concentrated in serum EV rather than free or forming complexes in serum, whereas $\mathrm{CRP}$ is present in both $\mathrm{EV}$ and free or forming complexes in serum (Fig. 2F). Moreover, these biomarkers and potentially others (Fig. 2A-E) can also be detected in whole serum by immunoblot (Fig. 2F), supporting their future screening using whole serum.

\section{CHARACTERIZATION OF EV FROM NHC AND CCA HUMAN CELLS IN VITRO}

$\mathrm{EV}$ were isolated from $\mathrm{NHC}, \mathrm{H} 69$, and two CCA human cells lines (i.e., EGI1 and TFK1); and they were characterized by TEM, western blot, NTA, and immunofluorescence. TEM images showed that the $\mathrm{EV}$ derived from $\mathrm{NHC}, \mathrm{H} 69$, and CCA cells exhibit a typical exosome-like round morphology (Fig. 3A). Size analysis of EV revealed mode diameters ( \pm standard error of the mean) of $152.9 \pm 6.0,167.7 \pm 2.0$, $143.8 \pm 10.5$, and $142.7 \pm 12.2$ for NHC, H69, and CCA cells (EGI1 and TFK1), respectively, with no statistically significant differences among them (Fig. $3 \mathrm{~B})$. The EV derived from the apical or basolateral membranes of the cells did not show size differences between NHC and CCA cells (data not shown). Interestingly, the amount of EV secreted from the apical membrane of the cells was markedly higher compared to the basolateral membrane in both $\mathrm{NHC}$ and CCA cells (Fig. 3C). Next, levels of exosome protein markers CD9, CD63, and CD81, determined by immunoblotting, were compared between $\mathrm{EV}$ and their corresponding WCEs. The EV fraction from all 
A

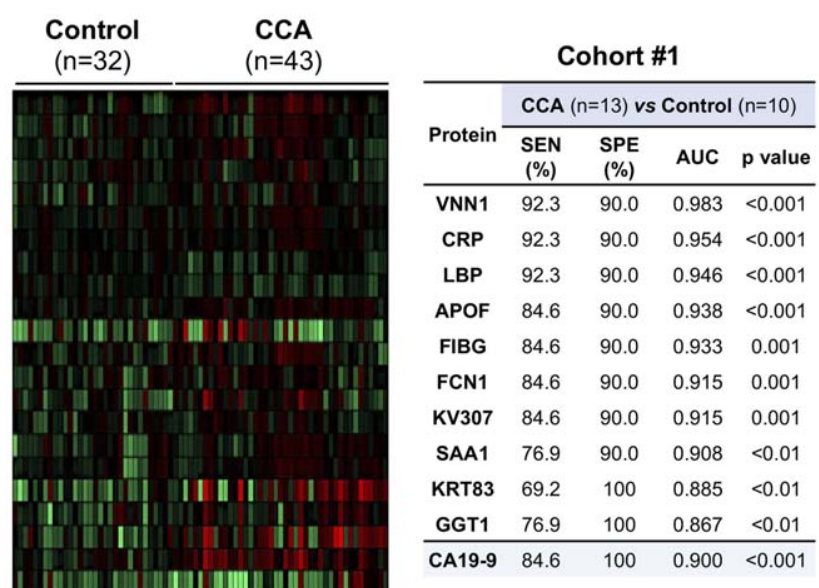

Cohort \#2

\begin{tabular}{ccccc}
\hline & \multicolumn{5}{c}{ CCA $(n=30)$ vs } & Control $(n=22)$ \\
\cline { 2 - 5 } Protein & $\begin{array}{c}\text { SEN } \\
(\%)\end{array}$ & $\begin{array}{c}\text { SPE } \\
(\%)\end{array}$ & AUC & p value \\
\hline PIGR & 83.3 & 100 & 0.945 & $<0.001$ \\
AMPN & 86.2 & 81.8 & 0.915 & $<0.001$ \\
FIBG & 93.3 & 72.7 & 0.845 & $<0.001$ \\
IGHA1 & 76.7 & 86.3 & 0.839 & $<0.001$ \\
VNN1 & 83.3 & 63.6 & 0.824 & $<0.001$ \\
IGHA2 & 83.3 & 72.7 & 0.824 & $<0.001$ \\
A1AT & 89.7 & 68.1 & 0.799 & $<0.001$ \\
LG3BP & 66.7 & 81.8 & 0.777 & 0.001 \\
GPC5C & 66.7 & 72.7 & 0.771 & 0.001 \\
PPBT & 73.3 & 68.1 & 0.764 & 0.001 \\
\hline CA19-9 & 82.8 & 100 & 0.936 & $<0.001$
\end{tabular}

All patients

\begin{tabular}{ccccc}
\hline \multirow{3}{*}{ Protein } & \multicolumn{5}{l}{ CCA $(n=43)$ vs } & Control $(n=32)$ \\
\cline { 2 - 5 } & $\begin{array}{l}\text { SEN } \\
(\%)\end{array}$ & $\begin{array}{c}\text { SPE } \\
(\%)\end{array}$ & AUC & $p$ value \\
\hline AMPN & 90.7 & 65.6 & 0.878 & $<0.001$ \\
VNN1 & 72.1 & 87.5 & 0.876 & $<0.001$ \\
PIGR & 83.7 & 71.8 & 0.844 & $<0.001$ \\
IGHA1 & 81.4 & 75.0 & 0.820 & $<0.001$ \\
CRP & 79.1 & 68.7 & 0.808 & $<0.001$ \\
GGT1 & 72.1 & 87.5 & 0.786 & $<0.001$ \\
IGHA2 & 72.1 & 78.1 & 0.775 & $<0.001$ \\
FIBG & 79.1 & 75.0 & 0.767 & $<0.001$ \\
NEP & 65.1 & 81.2 & 0.761 & $<0.001$ \\
GPC5C & 65.1 & 75.0 & 0.741 & $<0.001$ \\
\hline CA19-9 & 81.4 & 100 & 0.907 & $<0.001$
\end{tabular}

Cohort \#2

\begin{tabular}{ccccc}
\hline \multirow{2}{*}{ Protein } & \multicolumn{4}{l}{ CCA I-II $(n=13)$ vs Control $(n=22)$} \\
\cline { 2 - 5 } & $\begin{array}{c}\text { SEN } \\
(\%)\end{array}$ & $\begin{array}{c}\text { SPE } \\
(\%)\end{array}$ & AUC & p value \\
\hline PIGR & 75.0 & 95.4 & 0.905 & $<0.001$ \\
AMPN & 91.7 & 72.7 & 0.833 & $<0.01$ \\
FIBG & 100 & 68.1 & 0.833 & $<0.01$ \\
IGHG4 & 66.7 & 96.4 & 0.818 & $<0.01$ \\
IGHA1 & 91.7 & 59.0 & 0.814 & $<0.01$ \\
LG3BP & 75.0 & 77.2 & 0.807 & $<0.01$ \\
HV102 & 91.7 & 63.6 & 0.803 & $<0.01$ \\
A1AT & 83.3 & 72.7 & 0.788 & $<0.01$ \\
IGHA2 & 83.3 & 72.7 & 0.788 & $<0.01$ \\
SAMP & 75.0 & 86.3 & 0.784 & $<0.01$ \\
\hline CA19-9 & 81.8 & 100 & 0.916 & $<0.001$
\end{tabular}

Fold change

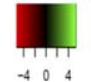

FIG. 2. Differential proteomic analysis of serum EV from CCA, PSC, and HCC patients and healthy individuals. (A) Heatmap of the proteins differentially expressed between the serum EV of CCA and healthy individuals and diagrams with the diagnostic capacity of the 10 selected biomarkers in cohort 1 , cohort 2, and cohort $1+2$ (all patients), as well as diagram of CCA I-II versus control (cohort 2). (B) Heatmap of the proteins differentially expressed between the serum EV of PSC and healthy individuals and diagrams with the diagnostic capacity of the 10 selected biomarkers in cohort 1 , cohort 2 , and cohort $1+2$ (all patients), as well as diagram of PSC patients without cirrhosis versus control (all patients). (C) Heatmap of the proteins differentially expressed between the serum EV of CCA and PSC patients and diagrams with the diagnostic capacity of the 10 selected biomarkers in cohort 1, cohort 2, and cohort $1+2$ (all patients), as well as diagram of CCA I-II versus PSC (all patients). (D) Heatmap of the proteins differentially expressed between the serum EV of HCC and healthy individuals and diagrams with the diagnostic capacity of the 10 selected biomarkers in cohort $1+2$ (all patients), as well as diagram of intrahepatic CCA versus HCC (all patients). *AFP, HCC versus intrahepatic CCA. (E) Box plot diagrams with the best protein biomarkers in serum EV of CCA, PSC, and HCC patients and healthy individuals. (F) Representative immunoblots of different selected biomarkers in serum EV, serum protein pellet (ultracentrifuged again after EV depletion), serum without EV, and total serum of CCA, PSC, and HCC patients and healthy individuals. The sensitivity, specificity, and AUC for the diagnosis of the classical nonspecific serum tumor markers CA19-9 and AFP were also determined. Abbreviations: GGT1, gamma-glutamyltransferase 1; ns, not significant; SEN, sensitivity; SPE, specificity.

cell types was enriched in these proteins (Fig. 3D). Finally, analysis of CD63 expression by immunofluorescence showed that both CCA cell lines (EGI1 and TFK1) display more CD63-positive vesicle aggregates in the cytoplasm than NHC and H69 cells (Fig. 3E). 
B

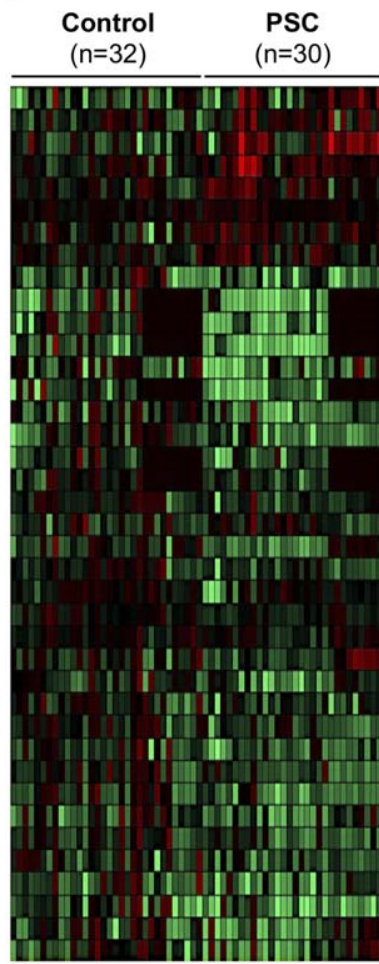

\begin{tabular}{ccccc}
\multicolumn{5}{c}{ Cohort \#1 } \\
\hline \multirow{5}{*}{ Protein $(n=9)$ vs } & Control $(n=10)$ \\
\cline { 2 - 5 } & $\begin{array}{c}\text { SEN } \\
(\%)\end{array}$ & $\begin{array}{c}\text { SPE } \\
(\%)\end{array}$ & AUC & p value \\
\hline NEP & 100 & 90.0 & 0.967 & 0.001 \\
APOF & 88.9 & 90.0 & 0.944 & 0.001 \\
FCN1 & 100 & 80.0 & 0.889 & $<0.01$ \\
A2ML1 & 77.8 & 90.0 & 0.889 & $<0.01$ \\
IGHD & 88.9 & 80.0 & 0.878 & $<0.01$ \\
LDHA & 88.9 & 80.0 & 0.867 & $<0.01$ \\
VNN1 & 77.8 & 90.0 & 0.867 & $<0.01$ \\
AMPE & 88.9 & 80.0 & 0.844 & $<0.05$ \\
BAIP2 & 100 & 70.0 & 0.844 & $<0.05$ \\
UGPA & 88.9 & 80.0 & 0.833 & $<0.05$ \\
\hline
\end{tabular}

\begin{tabular}{ccccc}
\multicolumn{5}{c}{ Cohort \#2 } \\
\hline \multirow{5}{*}{ Protein } & \multicolumn{3}{c}{ PSC $(n=21)$ vs } & Control $(n=22)$ \\
\cline { 2 - 5 } & $\begin{array}{l}\text { SEN } \\
(\%)\end{array}$ & $\begin{array}{c}\text { SPE } \\
(\%)\end{array}$ & AUC & p value \\
\hline PIGR & 90.5 & 68.2 & 0.864 & $<0.001$ \\
AMPN & 81.0 & 63.6 & 0.790 & 0.001 \\
GPC5C & 76.2 & 59.1 & 0.768 & $<0.01$ \\
KV401 & 81.0 & 68.1 & 0.766 & $<0.01$ \\
KV121 & 61.9 & 77.2 & 0.742 & $<0.01$ \\
KV309 & 85.7 & 50.0 & 0.742 & $<0.01$ \\
KNG1 & 76.2 & 72.7 & 0.736 & $<0.01$ \\
ABCBB & 66.7 & 86.4 & 0.732 & $<0.01$ \\
KV301 & 61.9 & 90.9 & 0.729 & 0.01 \\
IGKC & 81.0 & 54.5 & 0.729 & 0.01 \\
\hline & & & &
\end{tabular}

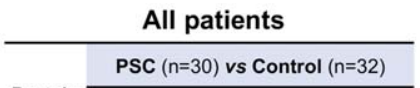

\begin{tabular}{ccccc}
\multicolumn{5}{c}{ All patients } \\
\hline \multirow{4}{*}{ Protein } & \multicolumn{5}{c}{$\begin{array}{c}\text { PSC non-cirrhotic }(n=24) \text { vs } \\
\text { Control }(n=32)\end{array}$} \\
\cline { 2 - 6 } & $\begin{array}{c}\text { SEN } \\
(\%)\end{array}$ & $\begin{array}{c}\text { SPE } \\
(\%)\end{array}$ & AUC & p value \\
\hline NEP & 70.8 & 90.6 & 0.806 & $<0.001$ \\
FCN1 & 70.8 & 78.1 & 0.790 & $<0.001$
\end{tabular}

\begin{tabular}{ccccccccccc} 
Protein & $\begin{array}{c}\text { SEN } \\
(\%)\end{array}$ & $\begin{array}{c}\text { SPE } \\
(\%)\end{array}$ & AUC & p value & & & $\begin{array}{c}\text { SEN } \\
(\%)\end{array}$ & $\begin{array}{c}\text { SPE } \\
(\%)\end{array}$ & AUC & p value \\
\hline AMPN & 83.3 & 62.5 & 0.789 & $<0.001$ & & NEP & 70.8 & 90.6 & 0.806 & $<0.001$ \\
FCN1 & 76.7 & 68.7 & 0.771 & $<0.001$ & & FCN1 & 70.8 & 78.1 & 0.790 & $<0.001$
\end{tabular}

$\begin{array}{llllllllll}\text { NEP } & 63.3 & 90.6 & 0.761 & <0.001 & \text { AMPN } & 83.3 & 65.6 & 0.781 & <0.001\end{array}$

$\begin{array}{llllllllll}\text { PIGR } & 76.7 & 71.8 & 0.742 & 0.001 & \text { VNN1 } & 79.2 & 56.2 & 0.758 & 0.001\end{array}$

$\begin{array}{llllllllll}\text { VNN1 } & 76.7 & 59.3 & 0.741 & 0.001 & \text { DPP4 } & 87.5 & 53.1 & 0.740 & <0.01\end{array}$

$\begin{array}{llllllllll}\text { GPC5C } & 63.3 & 75.0 & 0.733 & <0.01 & \text { IGHM } & 83.3 & 62.5 & 0.728 & <0.01\end{array}$

$\begin{array}{lllllllllll}\text { IGHM } & 86.7 & 62.5 & 0.732 & <0.01 & \text { HV206 } & 66.7 & 65.6 & 0.719 & <0.01\end{array}$

$\begin{array}{llllllllll}\text { KV301 } & 79.8 & 87.5 & 0.708 & <0.01 & \text { C1QA } & 75.0 & 59.3 & 0.710 & <0.01\end{array}$

Fold change

$\begin{array}{llllll}\text { A2MG } & 66.7 & 71.8 & 0.699 & <0.01\end{array}$

\begin{tabular}{lllll} 
BAIP2 & 66.7 & 62.5 & 0.696 & $<0.01$ \\
\hline
\end{tabular}

$\begin{array}{lllll}\text { PIGR } & 70.8 & 71.8 & 0.701 & <0.05\end{array}$

\begin{tabular}{lllll} 
CRP & 70.8 & 65.6 & 0.699 & $<0.05$ \\
\hline
\end{tabular}

FIG. 2. (Continued).

\section{COMPARATIVE PROTEOME CONTENT BETWEEN WCE AND EV DERIVED FROM NHC AND CCA HUMAN CELLS}

Differential mass spectrometry analysis was carried out to further characterize the protein content of $\mathrm{EV}$ and WCEs from NHC, H69, and CCA (i.e., EGI1 and TFK1) cells. A high number of proteins were identified in the WCEs and EV fractions of NHC, H69, and CCA cells. A total of 2,156 and 1,635 proteins were detected in the WCE and EV of EGI1 cells, respectively, and 1,926 and 1,322 proteins in the WCE and EV of TFK1 cells, respectively. On the other hand, 1,318 and 820 proteins were identified in WCE and EV of NHC and 2,870 and 1,440 proteins in WCE and EV of H69 cells, respectively (Fig. 4A). Of note, higher numbers of proteins were identified in
EV derived from the apical $(777,367$, and 450) compared to the basolateral $(82,142,8)$ membrane in EGI1, TFK1, and NHC, respectively (Fig. 4A). As expected, the EV fractions were enriched in $\mathrm{EV}$ protein biomarkers CD9, CD81, CD63, tumor susceptibility gene 101 protein, and Flotillin-1, among others (Supporting Table S3). Likewise, an increased number of proteins involved in vesicle physiology was present in $\mathrm{EV}$ isolated from all four cell types compared to their matched WCEs by GO analysis (Supporting Fig. S3).

Principal component analysis revealed different proteome profiles between samples (Fig. 4B). The WCE of both CCA cell lines (EGI1 and TFK1) has a closely related proteome but is different from both $\mathrm{NHC}$ and H69 cells. Notably, the H69 WCE proteome is more similar to CCA cells than to NHC. These tendencies were also found in the EV proteome of all four types of cell culture. All of these data indicate that the H69 


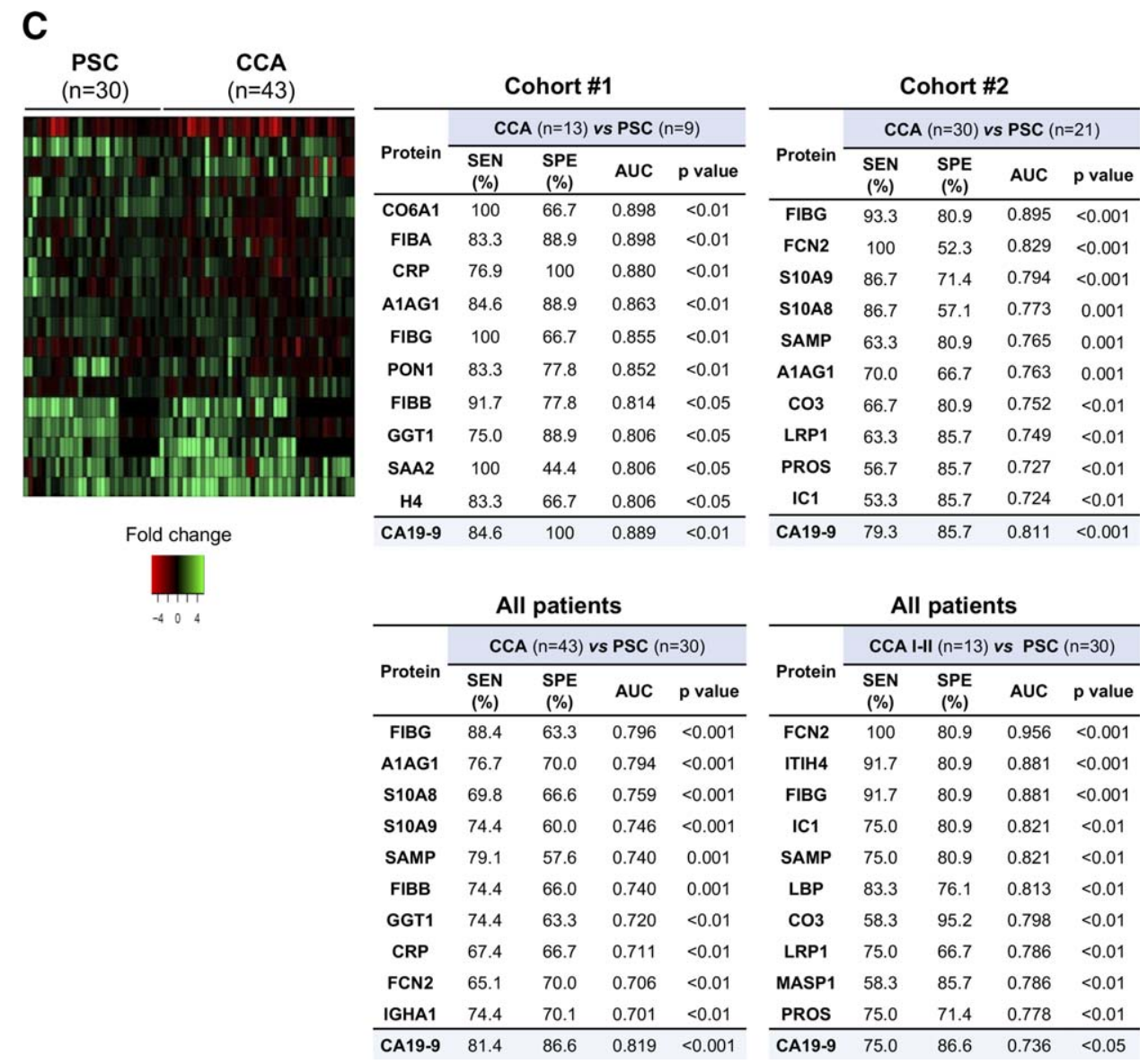

FIG. 2. (Continued).

cells present proteome profiles (in both $\mathrm{WCE}$ and $\mathrm{EV}$ ) more similar to CCA cells than to NHC. Considering this information, we performed proteomic selective comparative analysis between CCA cells and NHC. A total of 155 proteins were differentially expressed in EV of both CCA cell lines (EGI1 and TFK1) compared to NHC, and 108 of them were overexpressed in both CCA-derived EV (Fig. 4C). Then, functional characterization of the differentially expressed proteins was performed by using two different in silico bioinformatic softwares (i.e., DAVID and IPA) and bibliographic analysis of the proteins. GO annotations using the DAVID database indicated that a high number of the differentially expressed proteins are key players in different biological processes necessary for cancer development and progression, including cell proliferation, inflammation, survival, differentiation, and particularly processes related to the promotion of cell migration (Fig. 4D). These data were confirmed and expanded using the IPA bioinformatics software. The IPA software analysis linked the differential proteome of CCA-derived EV to the activation of several important pathways for cell migration such as integrin, Rho guanosine triphosphatases, integrin-linked protein kinase, Rho A, and Rac, which represent important drivers for cancer cell migration, invasion, and metastasis (Tables 1 and 2; Supporting Fig. S4). Moreover, the differential proteome of CCA-derived $\mathrm{EV}$ was also associated with cell proliferation and survival (Table 1). Individual analysis of these proteins revealed that CCA-derived EV contain key reported oncogenic proteins for CCA and other tumors (Fig. 4E), including epidermal growth factor receptor (EGFR), mucin-1 (MUC1), integrin beta-4 (ITGB4), CUB domaincontaining protein 1 , epithelial cell adhesion molecule, and calcium and integrin-binding protein 1 , among 


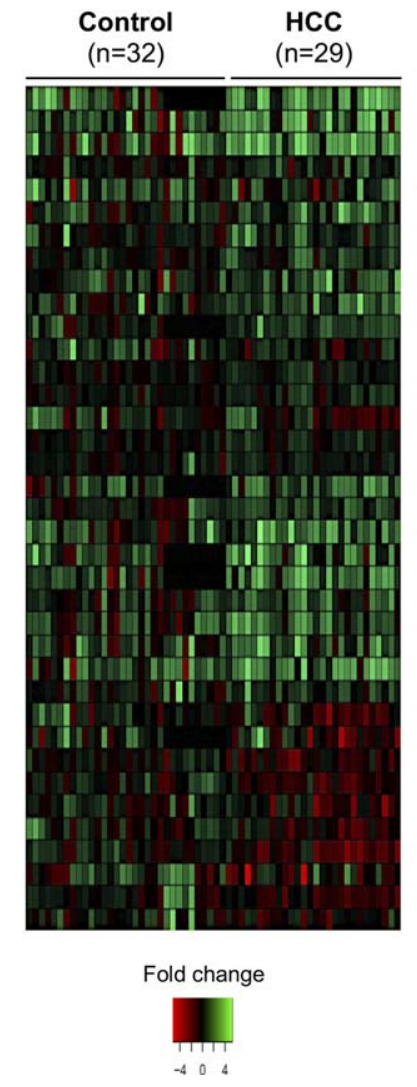

\begin{tabular}{|c|c|c|c|c|}
\hline \multirow[b]{3}{*}{ Protein } & \multicolumn{4}{|c|}{ All patients } \\
\hline & \multicolumn{4}{|c|}{ HCC $(n=29)$ vs Control $(n=32)$} \\
\hline & $\begin{array}{l}\text { SEN } \\
(\%)\end{array}$ & $\begin{array}{l}\text { SPE } \\
\text { (\%) }\end{array}$ & AUC & $\mathrm{p}$ value \\
\hline LG3BP & 96.6 & 71.8 & 0.904 & $<0.001$ \\
\hline PIGR & 82.8 & 71.8 & 0.837 & $<0.001$ \\
\hline A2MG & 92.9 & 56.2 & 0.796 & $<0.001$ \\
\hline IGHG3 & 62.1 & 84.3 & 0.767 & $<0.001$ \\
\hline FIBG & 78.6 & 75.0 & 0.756 & 0.001 \\
\hline HV103 & 89.7 & 50.0 & 0.727 & $<0.01$ \\
\hline SPTB1 & 65.5 & 75.5 & 0.719 & $<0.01$ \\
\hline LV001 & 60.7 & 81.2 & 0.709 & $<0.01$ \\
\hline APOE & 60.7 & 68.7 & 0.706 & $<0.01$ \\
\hline AMPN & 72.4 & 71.8 & 0,704 & $<0.01$ \\
\hline AFP & 82.1 & 64.0 & 0.802 & $<0.001$ \\
\hline
\end{tabular}

\begin{tabular}{ccccc}
\multicolumn{6}{c}{ All patients } \\
\hline \multirow{3}{*}{ Protein } & \multicolumn{5}{c}{ iCCA $(n=12)$} & vs HCC $(n=29)$ \\
\cline { 2 - 6 } & $\begin{array}{l}\text { SEN } \\
(\%)\end{array}$ & $\begin{array}{l}\text { SPE } \\
(\%)\end{array}$ & AUC & p value \\
\hline FIBG & 83.3 & 89.6 & 0.894 & $<0.001$ \\
A1AG1 & 83.3 & 82.1 & 0.845 & 0.001 \\
VTDB & 75.0 & 89.2 & 0.823 & 0.001 \\
CRP & 75.0 & 79.3 & 0.807 & $<0.01$ \\
VNN1 & 83.3 & 68.9 & 0.802 & $<0.01$ \\
A1BG & 83.3 & 68.9 & 0.799 & $<0.01$ \\
FIBB & 100 & 67.8 & 0.795 & $<0.01$ \\
CO9 & 75.0 & 71.4 & 0.753 & $<0.05$ \\
GPC5C & 75.0 & 62.0 & 0.747 & $<0.05$ \\
\hline CA19-9 & 75.0 & 91.3 & 0.801 & $<0.01$ \\
*AFP & 71.4 & 75.0 & 0.753 & $<0.05$
\end{tabular}

FIG. 2. (Continued).

others. Some of these proteins were particularly found in $\mathrm{EV}$ derived from the apical or basolateral membrane (Fig. 4E). Interestingly, several proteins, such as brainspecific angiogenesis inhibitor 1 -associated protein 2 , fibronectin 1, annexin A5, inter-alpha-trypsin inhibitor heavy chain $\mathrm{H} 2$, filamin $A$, and erythrocyte band 7 integral membrane protein, were similarly dysregulated in $\mathrm{EV}$ from CCA versus healthy individuals and in both CCA human cell lines compared to NHC (Fig. 4F).

\section{ANALYSIS OF THE PRESENCE OF HUMAN CCA-DERIVED EV IN SERUM OF MICE}

In order to evaluate if CCA tumor cells in the liver might secrete EV that can be present in serum, an orthotopic CCA model was generated by the implantation of human EGI1-derived CCA tumors into the liver of immunodeficient mice. Once the orthotopic tumor growth was confirmed by MRI (Fig. 5A), serum
$\mathrm{EV}$ were isolated and characterized by NTA and mass spectrometry analysis. NTA revealed no differences in serum EV size and concentration between mice with and without human CCA tumors in the liver (Supporting Fig. S5). Proteomic analysis indicated the presence of the EV markers CD9 and CD81 (data not shown) in the serum EV of both mouse experimental groups, with and without implanted CCA human tumors in their livers. A total number of 23 proteins of human origin with at least two different human peptides identified were detected in serum $\mathrm{EV}$ of mice with orthotopic human CCA tumors (Fig. 5B) but not in sham controls, of which nine were also present in CCA-derived EV in vitro (Fig. 5B).

\section{Discussion}

Current clinical needs in the management of CCA patients are focused on the search for new noninvasive tools for early and adequate diagnosis, as well as novel 


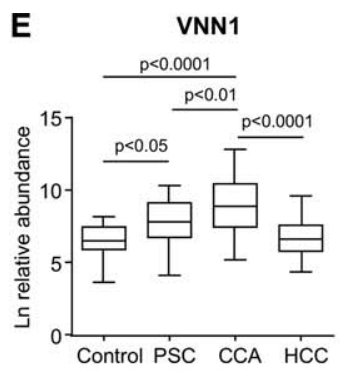

IGHA1
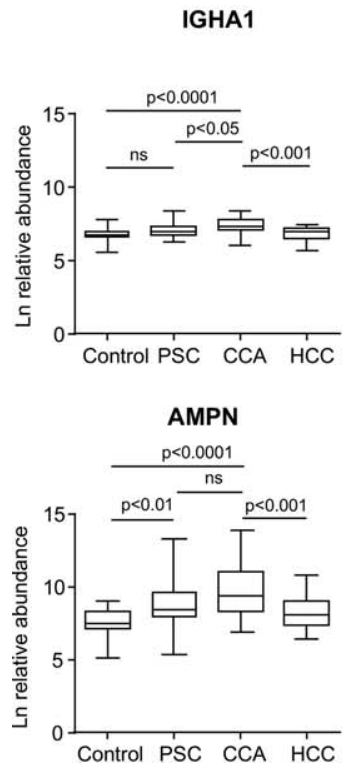

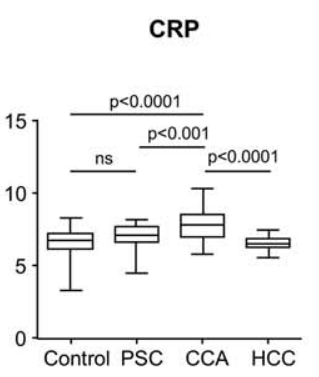

A1AG1
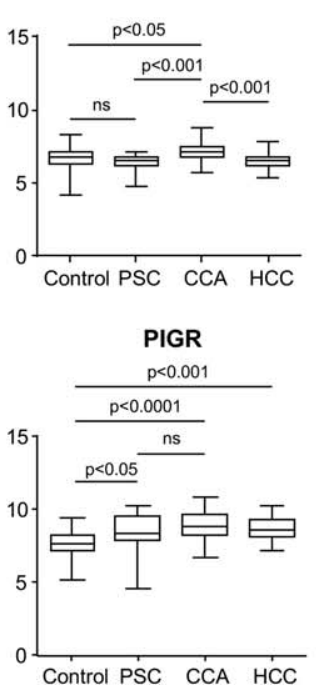
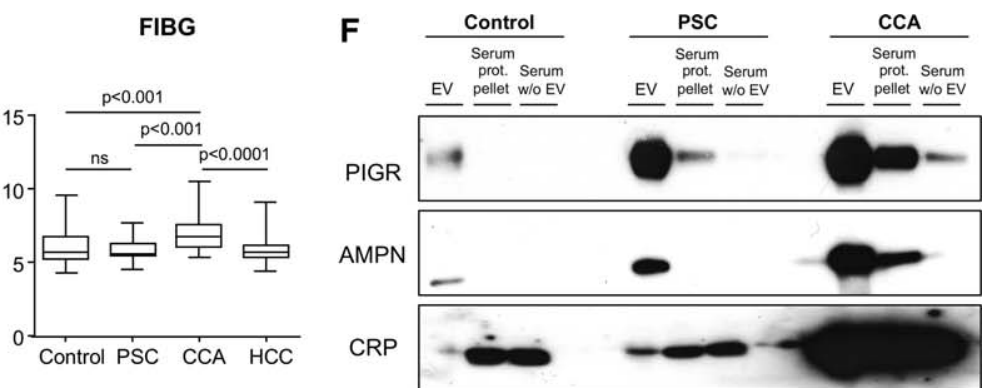

GGT1
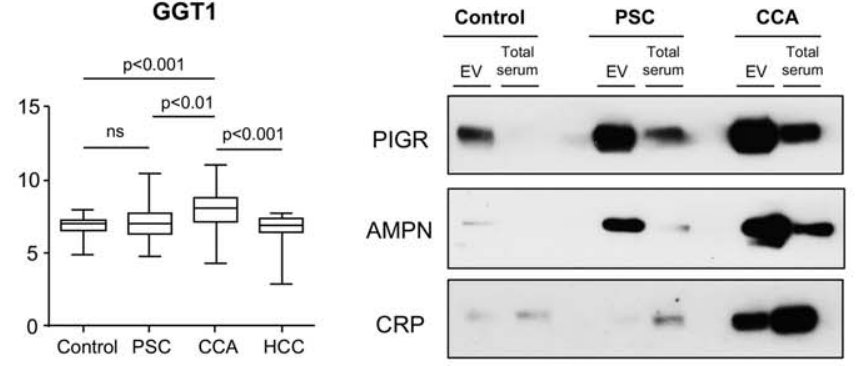

FIG. 2. (Continued).

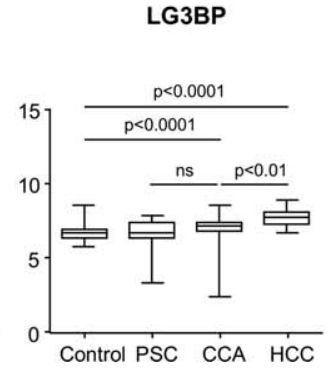

therapeutic options based on the underlying molecular mechanisms of tumorigenesis. The present study supports the concept that serum EV contain protein biomarker candidates for PSC, CCA, and HCC and that CCA-derived EV carry oncogenic proteins that may promote the growth and dissemination of these tumors.

Previous studies have evaluated the presence of protein biomarkers in bile, serum, and urine of CCA patients by liquid chromatography coupled to tandem mass-spectrometry. ${ }^{(17-19)}$ This high-throughput proteomic technique has become a powerful approach for biomarker discovery because it enables the identification and quantification of thousands of proteins within the same study. Nevertheless, while changes in the proteome profile were reported in bile and urine of CCA patients compared to control individuals, no good biomarker candidates resulted from the analysis of serum in CCA patients, probably as a consequence of the high abundance of common plasma proteins. ${ }^{(17,19-21)}$ To overcome this problem, we focused our attention on the serum EV fraction. We set up the conditions to isolate $\mathrm{EV}$ with high efficiency from only $1 \mathrm{~mL}$ of serum. The morphological and molecular features of these serum EV indicated that they were mainly exosomes, a fraction of $\mathrm{EV}$ derived from the multivesicular bodies of the cells by a dynamic and very precise mechanism. ${ }^{(7,8)}$ No differences in the serum EV concentration were obtained between CCA, PSC, and control individuals. However, an increased serum EV concentration was found in HCC patients compared to the other three groups, which is in line with other types of cancer and diseases such as diabetes, chronic kidney disease, and hypertension. ${ }^{(22,23)} \mathrm{EV}$ can be released to serum by multiple cell types including tumor cells. ${ }^{(24)}$ Here, we performed a proof of 


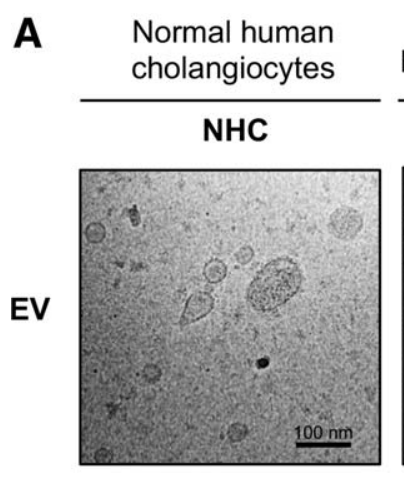

\section{SV-40 immortalized human cholangiocytes}
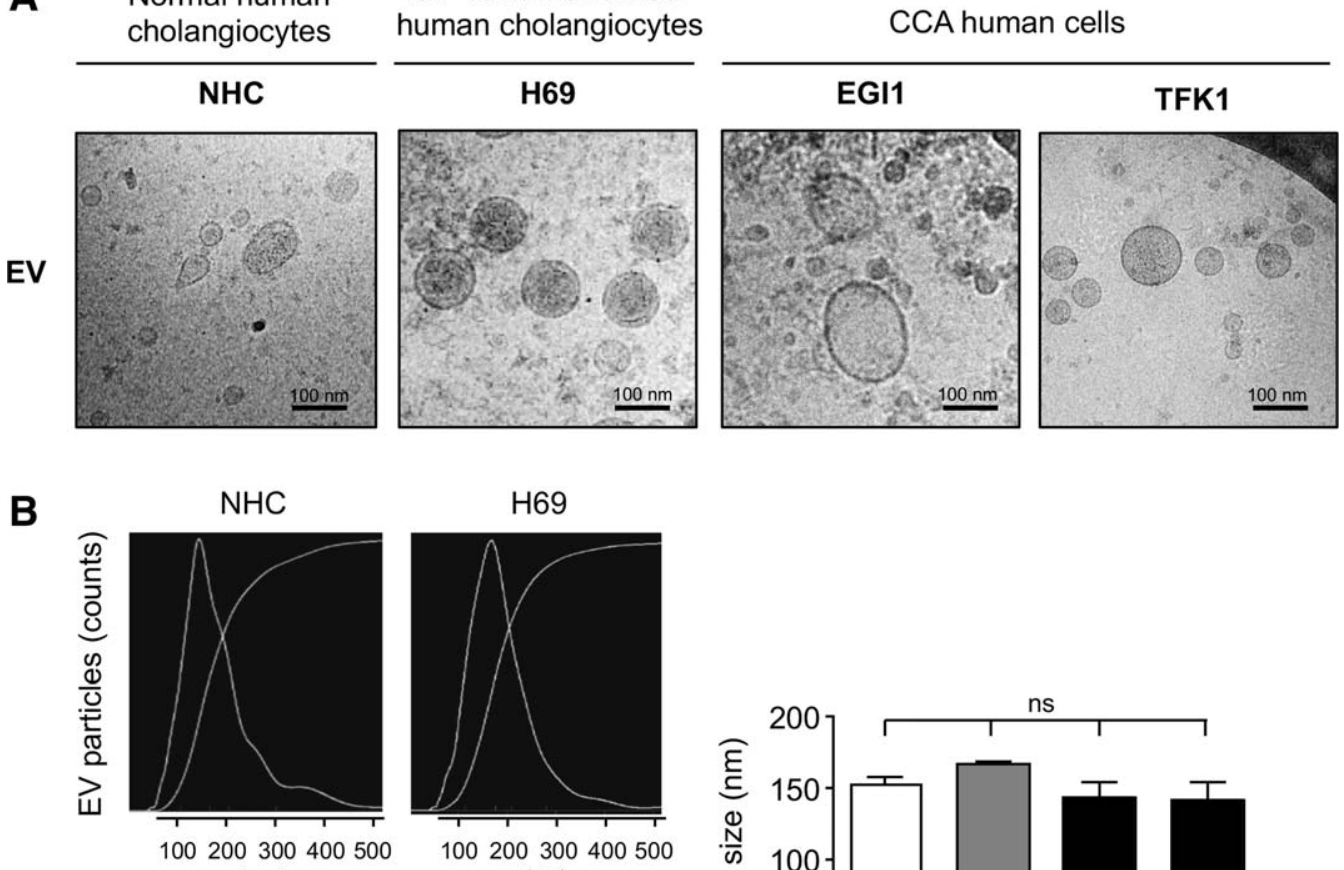

$(\mathrm{nm})$
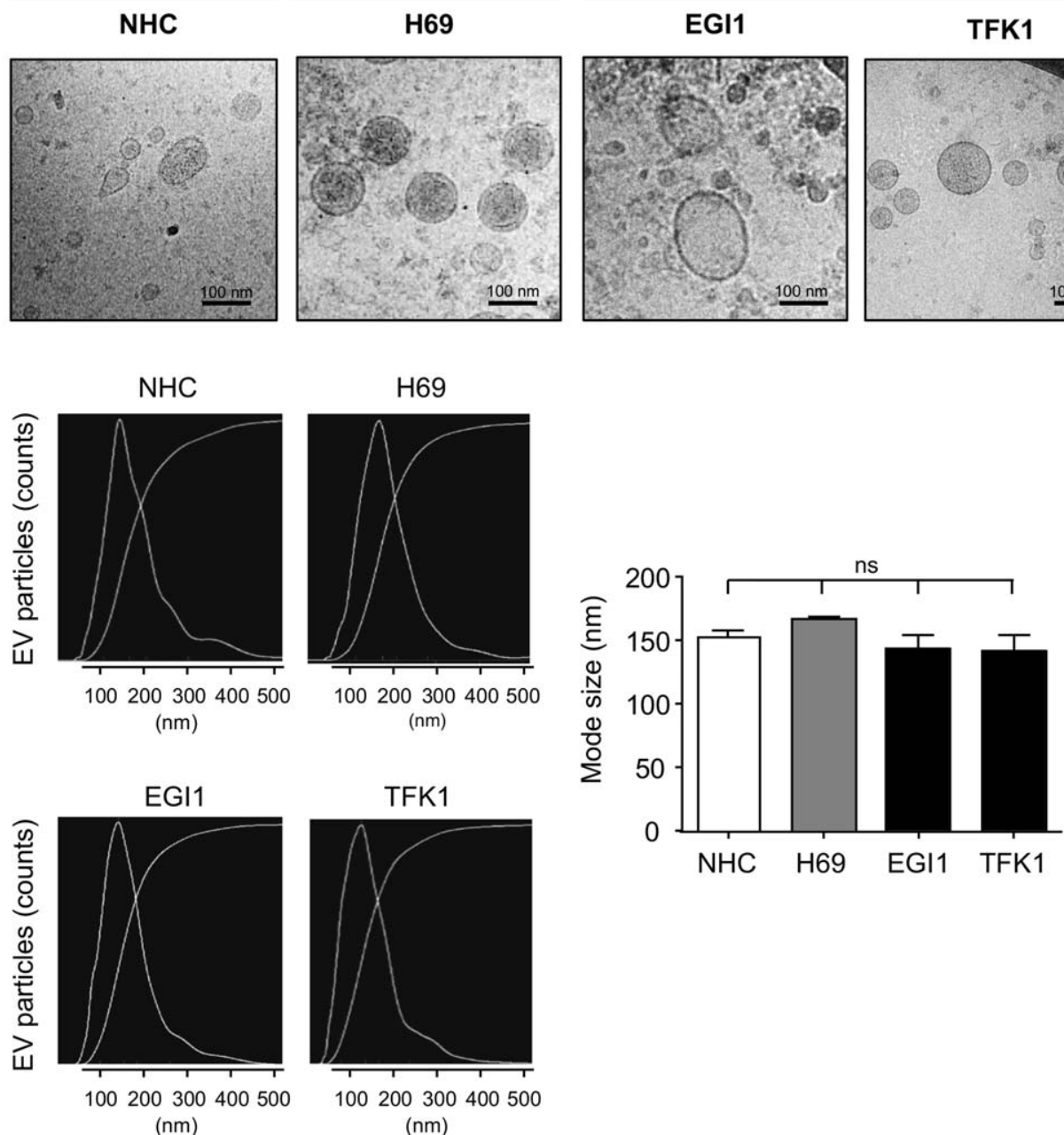

FIG. 3. Comparative analysis of the EV released by normal (NHC) and SV40-immortalized (H69) human cholangiocytes and by CCA human cells (EGI1 and TFK1). (A) TEM images of EV released by NHC, H69, EGI1, and TFK1 cells showing the typical exosome-round size $(\sim 150 \mathrm{~nm})$ and morphology. (B) NTA of EV released from NHC, H69, EGI1, and TFK1 cells revealing a similar EV mode $(\sim 150 \mathrm{~nm})$ between all four cell types. (C) EV concentration in the apical or basolateral media of NHC, EGI1, and TFK1 cells determined by NTA. (D) Representative immunoblots indicating that the EV isolated from NHC, H69, EGI1, and TFK1 cell cultures present enrichment of the EV markers CD9, CD63, and CD81 (positive controls) but do not contain the endoplasmic reticulum marker $78-\mathrm{kDa}$ glucose-regulated protein (negative control) compared to their own WCE. (D) Representative immunofluorescent images ( $\times 40$ magnification) of CD63-positive intracellular vesicles and quantification of fluorescence intensity indicating increased amount of CD63-positive intracellular vesicles in CCA cells (i.e., EGI1 and TFK1) compared to NHC and H69 cells. Nuclei were stained with 4',6-diamidino-2-phenylindole (blue). Abbreviations: AU, arbitrary units; DAPI, 4',6-diamidino-2-phenylindole; ER, endoplasmic reticulum; Grp78, 78-kDa glucose-regulated protein.

concept, identifying proteins of human origin in serum $\mathrm{EV}$ obtained from mice with orthotopic implant of human CCA cell tumors in the liver. These data strongly suggest that a proportion of $\mathrm{EV}$ present in the serum of CCA patients may be released by tumor cells and may provide specific proteins potentially useful for the diagnosis of CCA. Moreover, whether these EV are involved in CCA pathogenesis is a question that deserves further investigation.

Current noninvasive approaches have demonstrated low accuracy for the diagnosis of CCA, PSC, and HCC. Elevation of the serum tumor marker CA19-9 


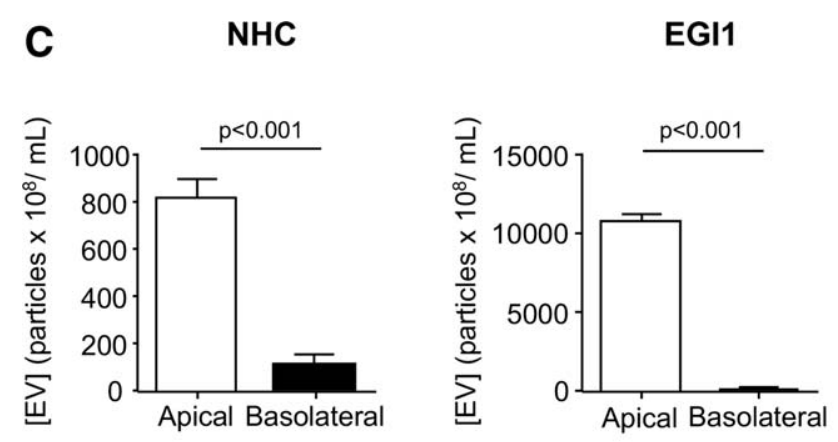

\section{TFK1}
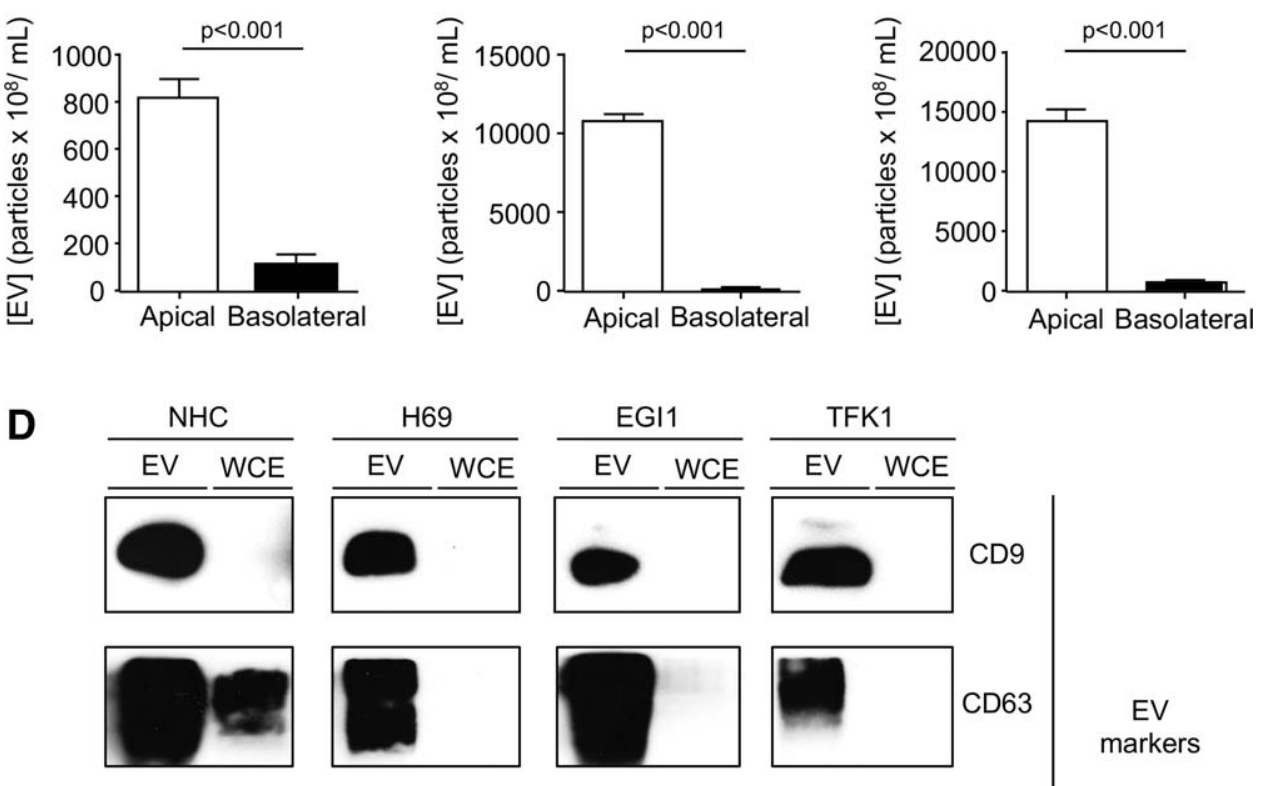

CD63

EV
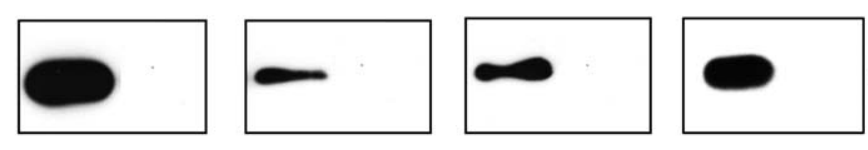

CD81
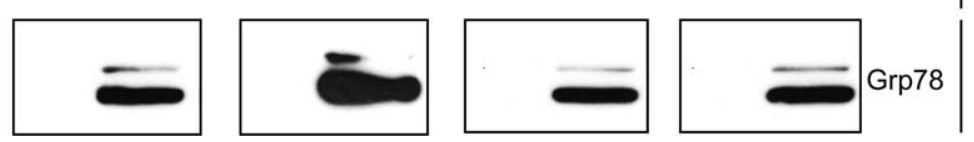

ER

marker

FIG. 3. (Continued).

is commonly used to support the diagnosis of CCA and for monitoring tumor progression. However, the specificity of this marker is low because $\sim 30 \%$ of PSC patients with elevated CA19-9 are CCA-free for a long period. ${ }^{(3,25)}$ In addition, increased serum CA19-9 levels are characteristic of bacteria-related cholangitis, other types of cancer, polycystic liver diseases, and smoking; and CA19-9 is not produced in $~ 10 \%$ of the population. ${ }^{(25)}$ In this regard, several studies have reported heterogeneous CA19-9 values ranging between $31 \%$ and $100 \%$ specificity and between $38 \%$ and $100 \%$ sensitivity in CCA. ${ }^{(25,26)}$ On the other hand, the distinction between PSC-associated biliary strictures and CCA early-stage lesions by MRI is also complicated, ${ }^{(2,3)}$ and invasive biliary brushing by endoscopic retrograde cholangiography used for conventional cytology and/or fluorescent in situ hybridization have only moderate diagnostic accuracy and are not generally considered due to procedure-related complications such as pancreatitis and cholangitis. ${ }^{(2,3)}$ In $\mathrm{HCC}$, the serum tumor marker AFP provides low diagnostic value but is considered in the follow-up when patients showed previous increased levels. ${ }^{(27)}$ In the present report, a differential proteome profile was identified in serum EV of CCA, PSC, HCC, and healthy individuals. Several proteins with differential degrees of abundance were found in serum EV of CCA versus healthy individuals, some of them with significant diagnostic potential, such as AMPN, VNN1, and PIGR. Similarly, serum EV of PSC patients are enriched in different proteins, some of them such as AMPN, FCN1, and neprilysin with diagnostic capacity. In addition, some of the proteins differentially identified in serum EV of CCA versus PSC patients presented differential diagnostic capacity, such as FIBG, A1AG1, and S100A8. Importantly, some biomarkers (i.e., FCN2, inter-alpha-trypsin inhibitor heavy chain $\mathrm{H} 4$, and FIBG) show higher 

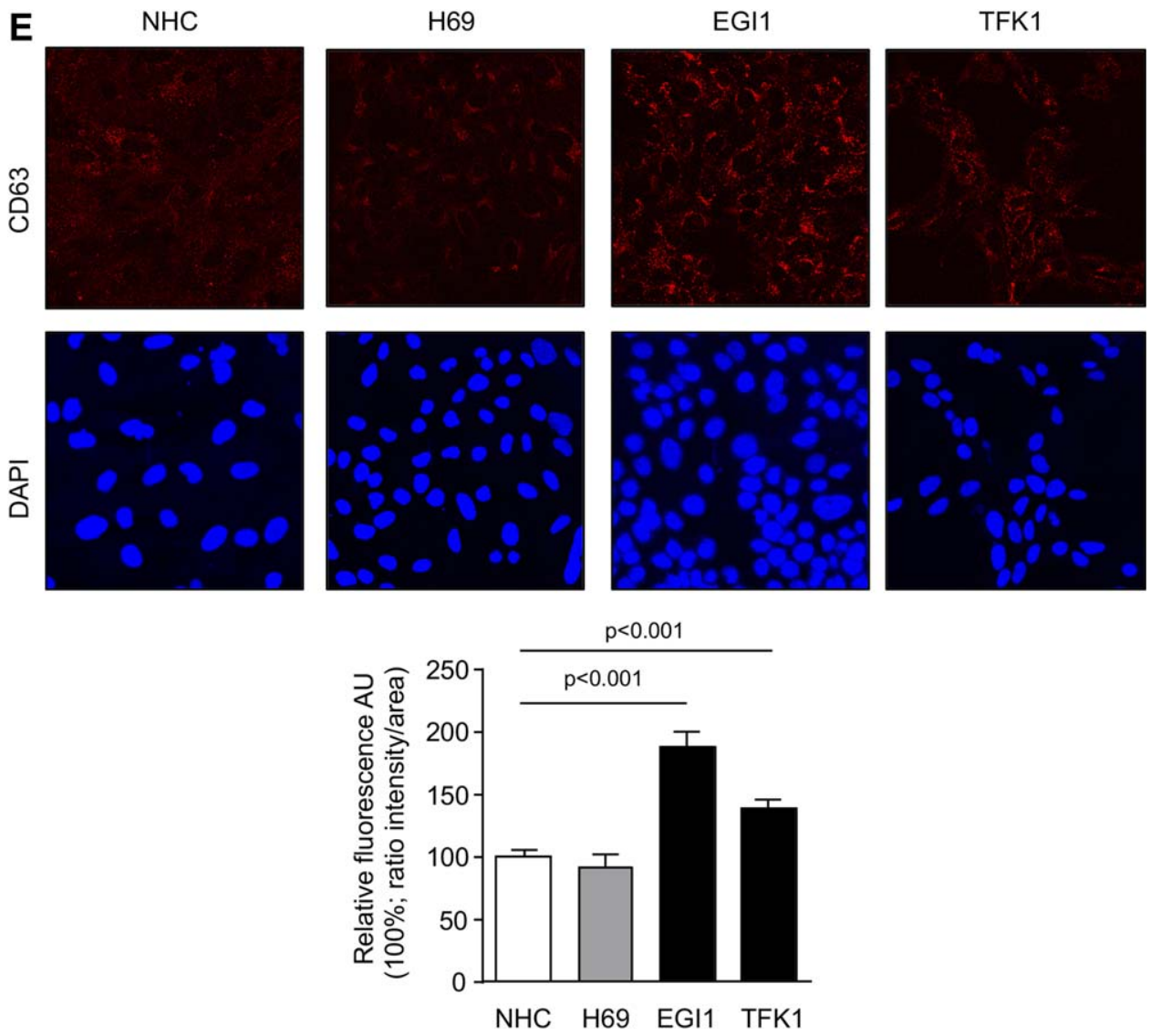

FIG. 3. (Continued).

diagnostic values in early-stage CCA (I-II) versus PSC patients than CA19-9. Likewise, of particular interest are VNN1, CRP, FIBG, IGHA1, and A1AG1 proteins, which are up-regulated only in serum $\mathrm{EV}$ of CCA patients compared to all PSC, HCC, and control individuals, highlighting their potential diagnostic value. Of note, several studies have pointed out the bad prognostic value of increased CRP levels in total serum of CCA patients ${ }^{(28-30)}$ and the role of AMPN (also called CD13) as a liver cancer stem cell marker. ${ }^{(31)}$ On the other hand, in HCC both LG3BP and PIGR showed higher diagnostic capacity than AFP. Interestingly, both LG3BP and PIGR are oncogenic proteins that promote HCC progression, tumor cell transformation, invasion, and proliferation ${ }^{(32,33)}$; and LG3BP has also been proposed as a bad prognostic biomarker for $\mathrm{HCC}{ }^{(34)}$

Our findings are consistent with a previous report indicating that $\mathrm{EV}$ in human bile may serve as a noninvasive tool for the diagnosis of CCA as they contain a specific panel of microRNAs with diagnostic value. $^{(18)}$ We reckon that well-designed prospective studies are now needed to perform in-depth investigations concerning their clinical value. These analyses should include, for example, combinations of selected markers together with the already available CA19-9 or AFP markers. Therefore, owing to the urgent need for good diagnostic biomarkers for CCA, PSC, and HCC, particularly in early stages, these new findings should be confirmed in the near future by further international studies with large cohorts of patients. Moreover, evaluation of protein biomarker candidates in serum EV of CCA or HCC patients before and after tumor resection may provide valuable information on their potential value as early diagnostic biomarkers of tumor recurrence as well as on the prognosis after surgery.

Regarding the role of $\mathrm{EV}$ in CCA pathogenesis, recent reports have shown that CCA-derived EV are 
A

WCE

Total proteins: 3501

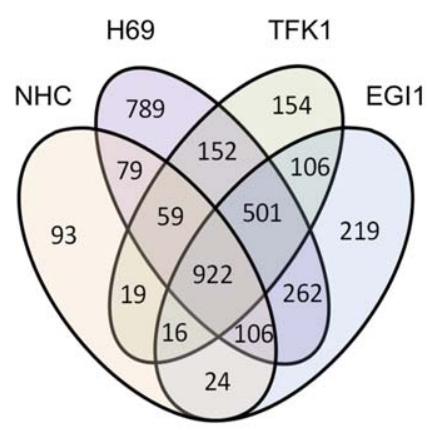

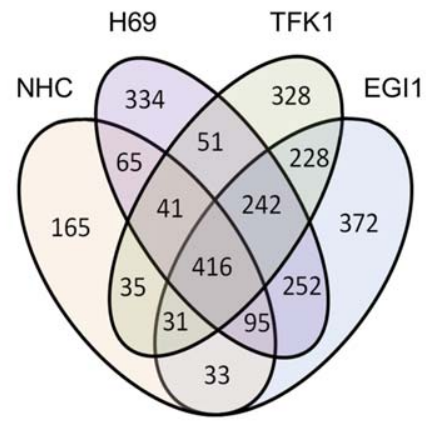

EV

Total proteins: 2688

H69
WCE

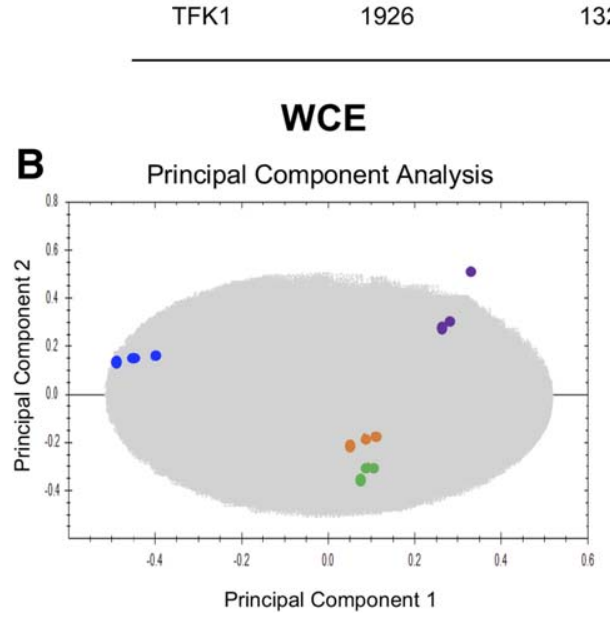

\# proteins apical (AP) vs basolateral (BL)

AP: 450

BL: 8

AP \& BL: 60

AP: 777

BL: 82

AP \& BL: 250

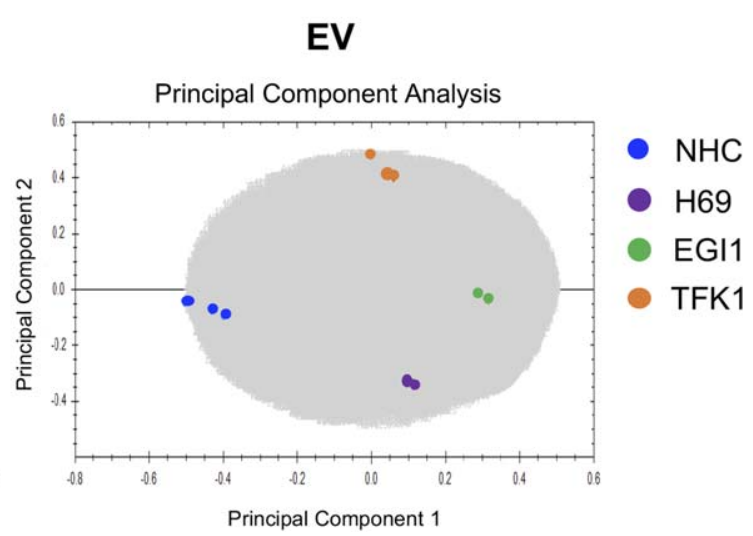

FIG. 4. Differential proteomic analysis of WCEs and EV released by normal (NHC) and SV40-immortalized (H69) human cholangiocytes and by CCA human cells (EGI1 and TFK1). (A) Venn diagrams showing the number of proteins identified for each comparison and total proteins identified in each case. (B) Principal component analysis of the proteome similarities between WCEs and EV derived from NHC, H69, EG1, and TFK1 cells. (C) Heatmaps of the differentially expressed proteins between CCA cell lines (i.e., EGI1 and TFK1) and NHC WCEs and EV (in triplicate). (D) Biological processes of the differentially expressed proteins between the EV of CCA cell lines (i.e., EGI1 and TFK1) and NHC were related to tumorigenesis and cell migration by GO analysis. (E) List of selected oncogenic proteins found overexpressed in EV released from CCA cells (both EGI1 and TFK1) compared to NHC and their abundancies in apical versus basolateral EV. Selected oncogenic proteins have been reported to be up-regulated in CCA tissue and/or in other tumors. (F) Similar dysregulated proteins in EV of CCA cells (both EGI1 and TFK1) compared with $\mathrm{NHC}$ and in serum EV of CCA versus healthy individuals, with their corresponding AUC values.

able to regulate the microenvironment and growth of these tumors. In particular, CCA-derived EV were shown to stimulate secretion of the proinflammatory cytokine interleukin- 6 by mesenchymal stem cells, further promoting the growth of CCA cells. ${ }^{(35)} \mathrm{CCA}-$ derived $\mathrm{EV}$ also stimulate the invasion and migration 

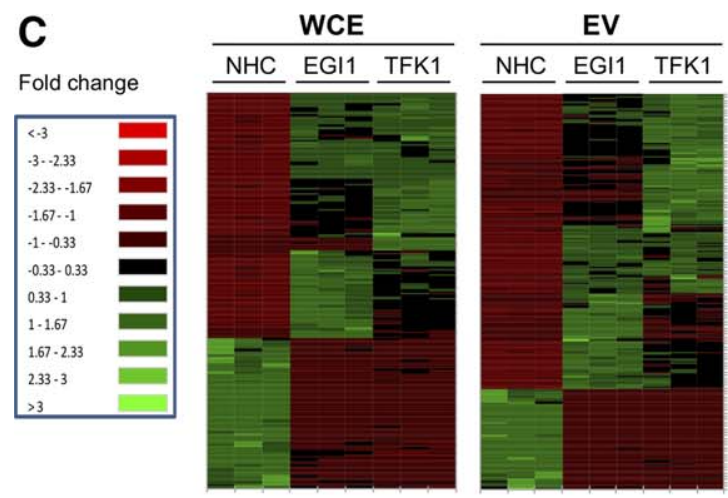

D Biological processes related to tumorigenesis

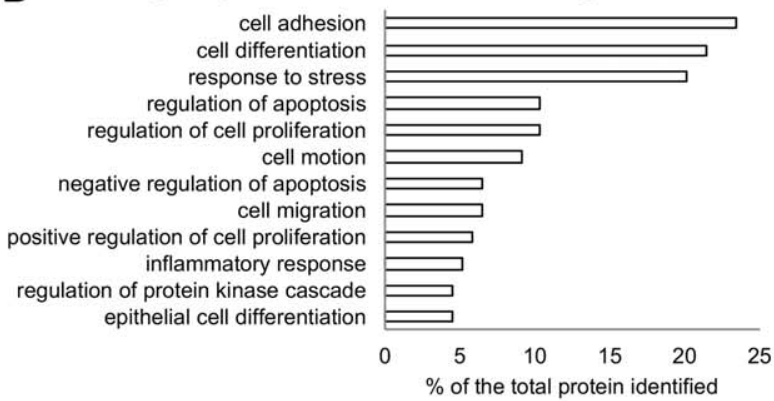

Biological processes related to cellular migration

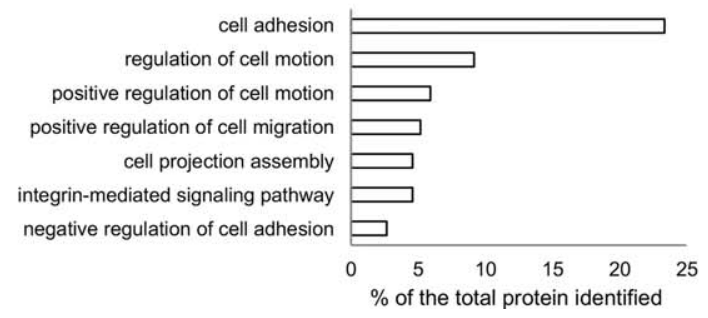

E

\begin{tabular}{ccccc}
\hline \multicolumn{5}{c}{ EV } \\
\hline \multirow{2}{*}{ Protein } & \multicolumn{4}{c}{ Fold change } \\
\cline { 2 - 5 } & EG11/NHC & $\begin{array}{c}\text { EGI1 } \\
\text { APIBL }\end{array}$ & TFK1/NHC & TFK1 APIBL \\
\hline EGFR & 11 & 7.66 & 106 & 0.76 \\
Mucin-1 & 39 & Only AP & 12 & 0.16 \\
Integrin $\beta 4$ & 20 & 2.73 & 19 & 2.88 \\
EPCAM & 120 & 3.33 & 188 & 1.38 \\
Agrin & 22 & Only AP & 12 & Not detected \\
CIB1 & 463 & Only AP & 517 & Only AP \\
EPS8 & 14 & Only AP & 22 & 0.21 \\
TACSTD2 & 70 & 4.5 & 32 & 0.9 \\
CDCP1 & 6 & 7.5 & 61 & 0.77 \\
ADAM10 & 22 & 5.5 & 5 & 0.29 \\
\hline
\end{tabular}

$\mathbf{F}$

\begin{tabular}{ccccccccc}
\hline \multicolumn{7}{c}{ Common dysregulated proteins in serum EV of CCA patients and EV-derived from CCA cells } \\
\hline Protein & $\begin{array}{c}\text { Fold change: } \\
\text { serum EV } \\
\text { CCA vs } \\
\text { control }\end{array}$ & AUC & p value & $\begin{array}{c}\text { Fold change EV: } \\
\text { EGI1 vs NHC }\end{array}$ & p value & $\begin{array}{c}\text { Fold change } \\
\text { TFK1 vs NHC }\end{array}$ & p value \\
\hline BAIAP2 & 2.14 & 0.735 & $<0.01$ & 65.15 & $<0.0001$ & 55.32 & $<0.0001$ \\
FN1 & 0.62 & 0.242 & $<0.01$ & 0.023 & $<0.0001$ & 0.042 & $<0.0001$ \\
ANXA5 & 0.28 & 0.283 & $<0.001$ & 0.201 & $<0.001$ & 0.1 & $<0.001$ \\
ITIH2 & 0.77 & 0.390 & $<0.05$ & 0.07 & $<0.0001$ & 0.09 & $<0.0001$ \\
FLMA & 0.23 & 0.366 & $<0.001$ & 0.24 & $<0.0001$ & 0.24 & $<0.0001$ \\
STOM & 0.47 & 0.356 & $<0.05$ & 0.12 & $<0.0001$ & 0.087 & $<0.0001$ \\
\hline
\end{tabular}

FIG. 4. (Continued).

of these cancer cells. ${ }^{(36)}$ Moreover, EV participate in the trafficking of specific microRNA species between cancer-associated fibroblasts and CCA cells, thus regulating tumor growth. ${ }^{(37)}$ Here, we characterized the $\mathrm{EV}$ released from $\mathrm{NHC}, \mathrm{H} 69$, and two CCA human cell lines. Our data indicated that most EV released by NHC, H69, and CCA cells show exosome-like features. Of note, both CCA human cell lines presented increased concentration of CD63-positive vesicles in the cytoplasm compared to NHC and H69 cells. Proteomic analysis of $\mathrm{EV}$ revealed that the profile of CCA-derived EV is quite similar between the two human CCA cell lines (i.e., EGI1 and TFK1) but different from NHC and H69 cells. Proteomic evaluation of CCA cell-derived EV revealed a common enrichment in oncogenic proteins in both tumor cell lines compared to NHC. Some of these oncogenic proteins have been associated with the promotion of tumor cell proliferation, invasion, and migration, such as EGFR, ITGB4, agrin, EGFR kinase substrate 8, tumorassociated calcium signal transducer 2, CUB domaincontaining protein 1 , disintegrin and metalloproteinase domain-containing protein 10, and epithelial cell adhesion molecule. Of note, the expression of EGFR, ${ }^{(38)}$ ITGB4, ${ }^{(39)}$ agrin, ${ }^{(40)}$ epithelial cell adhesion molecule, ${ }^{(41)}$ EGFR kinase substrate $8,{ }^{(42)}$ tumorassociated calcium signal transducer $2,{ }^{(43)}$ and MUC1, ${ }^{(44,45)}$ which are bad prognostic factors for CCA, was up-regulated in CCA tissue, supporting the notion that CCA-derived $\mathrm{EV}$ may be a reflection of the tumor features. Of special interest are EGFR, MUC1, and ITGB4. EGFR is found up-regulated in 
FIG. 5. Identification of human proteins in serum EV of a human CCA orthotopic mouse model. (A) Representative light and MRI images of the liver from an immunodeficient mouse with orthotopic implantation of CCA human tumors originated after subcutaneous injection of EGI1 human cells in immunodeficient mice. MRIs were taken after tumor implantation as well as 1 and 2 months later, when the blood was collected. (B) Human proteins identified by proteomic analysis in serum EV from the human CCA orthotopic mouse model but not in sham control mice, which are also detected in EV derived from CCA cells (EGI1) in vitro. (C) Working model: CCA-derived EV overexpress different oncogenic proteins that may be involved in the promotion of tumor growth and invasion/ metastasis. These CCA-derived EV may be also present in blood serum of patients and, together with other specific serum EV present in CCA patients, may provide new specific protein biomarkers for diagnosis.

\section{A}

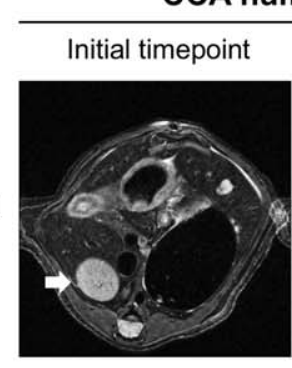

CCA human orthotopic mouse model

MRI
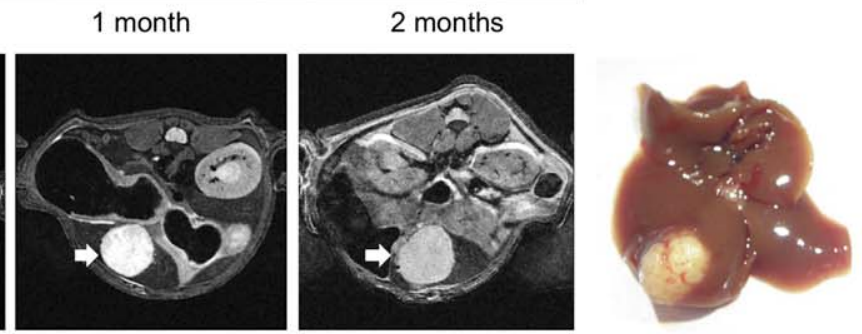

B

\begin{tabular}{ccc}
\hline $\begin{array}{c}\text { Human proteins identified only in } \\
\text { CCA orthotopic mice }\end{array}$ & $\begin{array}{c}\text { Presence in } \\
\text { EGl1-derived EV }\end{array}$ & $\begin{array}{c}\text { Presence in } \\
\text { serum EV of } \\
\text { CCA patients }\end{array}$ \\
\hline $\begin{array}{c}\text { Alpha-2-macroglobulin } \\
\text { Galectin-3-binding protein }\end{array}$ & Yes & Yes \\
Fibronectin & Yes & Yes \\
Complement C3 & Yes & Yes \\
Alpha-aminoadipic semialdehyde \\
dehydrogenase & Yes & Yes \\
Pyruvate kinase PKM & Yes & No \\
Clusterin & Yes & Yes \\
Alpha-enolase & Yes & Yes \\
Annexin A1 & Yes & Yes \\
\hline
\end{tabular}

C

- CCA cell-derived EV

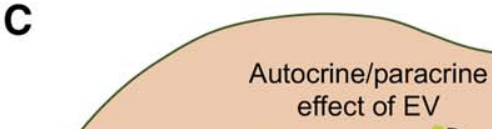

CCA cells

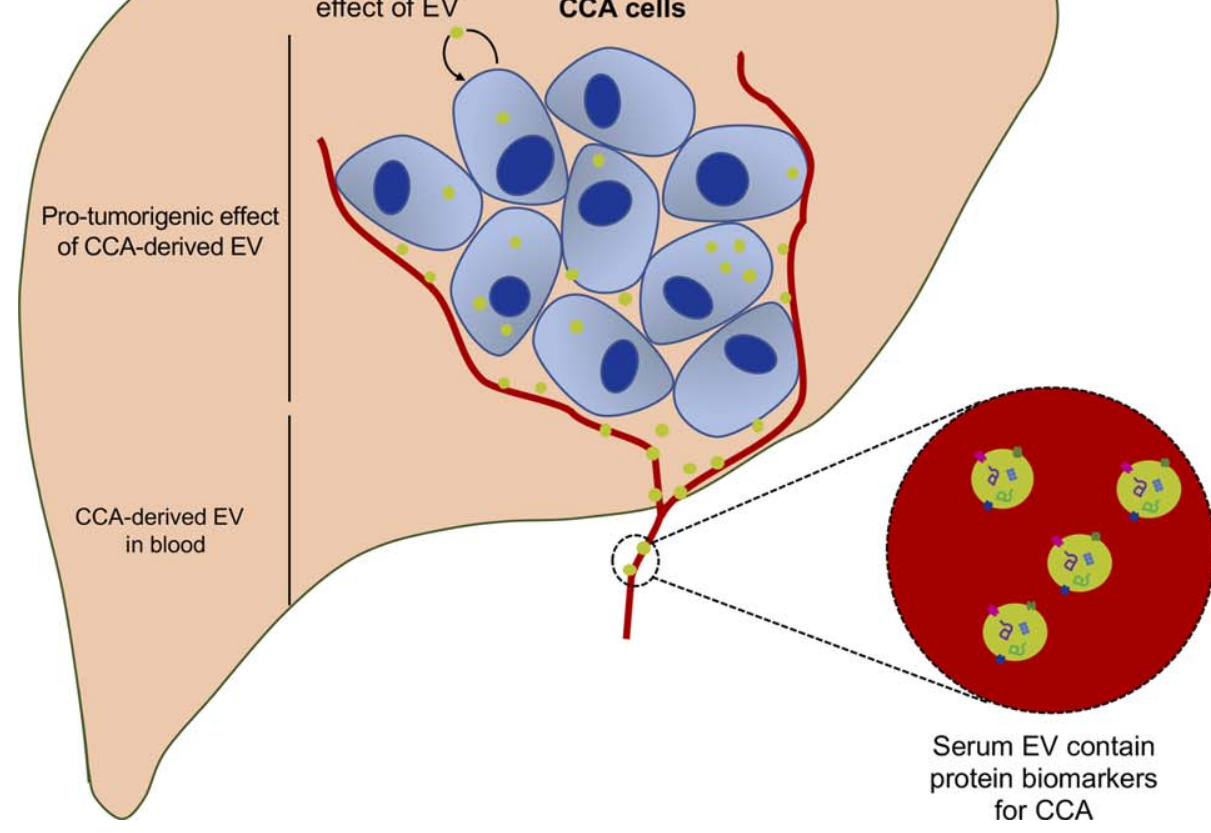


TABLE 1. IPA of Differentially Expressed Proteins in CCA-Derived EV Compared to NHC

\begin{tabular}{lrr} 
Biological Functions & $Z$ Score & $-\log P$ \\
\hline Invasion & 2.16 & 5.65 \\
Dissemination & 1.99 & 4.18 \\
Proliferation & 2.55 & 24.29 \\
Cell death & -2.18 & 10.66
\end{tabular}

Biological functions related to tumor processes by IPA software. $Z$ score represents the activation state of the upstream regulators related to such biological process (positive numbers represent activation and negative numbers, inactivation). $P$ values are represented as $-\log P$ values.

CCAs, promoting the growth, dedifferentiation, and invasion/migration of tumor cells, being considered a bad prognostic factor. ${ }^{(38)}$ MUC1, also found upregulated in CCAs, promotes CCA proliferation and metastasis and correlates with poor outcomes. ${ }^{(44,45)}$ In addition, ITGB4, an integrin essential for the specific determination of the tumor metastasis location, promotes the preferential organotropism of tumor cells. ${ }^{(39)}$ The high abundance of these three oncogenic proteins in CCA-derived EV suggests their potential key role in the promotion of CCA cell and stroma growth, as well as in tumor cell dissemination. However, further studies are needed to clarify the particular role of all these proteins found up-regulated in CCA-derived $\mathrm{EV}$ and their potential therapeutic regulatory value.

TABLE 2. IPA of Differentially Expressed Proteins in CCADerived EV Compared to NHC

\begin{tabular}{|c|c|c|c|}
\hline $\begin{array}{l}\text { Canonical } \\
\text { Pathway }\end{array}$ & $\begin{array}{c}Z \\
\text { Score }\end{array}$ & $\begin{array}{c}-\log \\
P\end{array}$ & Biological Function \\
\hline Integrin signaling & 1.63 & 3.14 & $\begin{array}{l}\text { Related to poor prognosis, } \\
\text { proliferation, apoptosis } \\
\text { resistance, promotion of } \\
\text { invasion, and metastasis }\end{array}$ \\
\hline $\begin{array}{l}\text { Signaling by Rho } \\
\text { family GTPases }\end{array}$ & 2.12 & 5.89 & $\begin{array}{l}\text { Promotion of migration, } \\
\text { invasion, cell } \\
\text { transformation, survival, } \\
\text { angiogenesis, and } \\
\text { metabolism }\end{array}$ \\
\hline ILK signaling & 1.89 & 4.15 & $\begin{array}{l}\text { Proliferation, survival, } \\
\text { migration, and invasion }\end{array}$ \\
\hline RhoA signaling & 2.00 & 1.90 & Migration and invasion \\
\hline Rac signaling & 2.24 & 2.99 & $\begin{array}{l}\text { Regulation of intercellular } \\
\text { adhesion, cell polarity, cell } \\
\text { migration, proliferation, } \\
\text { and survival }\end{array}$ \\
\hline
\end{tabular}

Predicted activation of canonical pathway based on proteins present in CCA EV, calculated with IPA software. $Z$ score represents the activation state of the upstream regulator of the pathway (positive numbers represent activation and negative numbers, inactivation). $P$ values are represented as $-\log P$ values. Abbreviation: GTPase, guanosine triphosphatase.
In sum (Fig. 5D), this study provides evidence that serum EV contain specific proteins with potential diagnostic and prognostic value for CCA, PSC, and HCC, opening new opportunities for their potential use as novel noninvasive tools. CCA-derived EV may be found in serum of patients and carry oncogenic proteins that could participate in the progression and dissemination of CCA. Manipulation of CCA-derived EV may represent a potential therapeutic strategy that deserves future investigation.

Acknowledgment: We thank the technical assistance of Dr. David Gil (CIC bioGUNE EM platform) for the acquisition of the cryo-electron images.

\section{REFERENCES}

1) Banales JM, Cardinale V, Carpino G, Marzioni M, Andersen JB, Invernizzi P, et al. Expert consensus document. Cholangiocarcinoma: current knowledge and future perspectives consensus statement from the European Network for the Study of Cholangiocarcinoma (ENS-CCA). Nat Rev Gastroenterol Hepatol 2016;13:261-280.

2) Razumilava N, Gores GJ. Cholangiocarcinoma. Lancet 2014; 383:2168-2179.

3) Razumilava N, Gores GJ. Surveillance for cholangiocarcinoma in patients with primary sclerosing cholangitis: effective and justified? Clin Liver Dis (Hoboken) 2016;8:43-47.

4) Hirschfield GM, Karlsen TH, Lindor KD, Adams DH. Primary sclerosing cholangitis. Lancet 2013;382:1587-1599.

5) Karlsen TH, Boberg KM. Update on primary sclerosing cholangitis. J Hepatol 2013;59:571-582.

6) Lazaridis $\mathrm{KN}$, LaRusso NF. Primary sclerosing cholangitis. N Engl J Med 2016;375:1161-1170.

7) Yanez-Mo M, Siljander PR, Andreu Z, Zavec AB, Borras FE, Buzas EI, et al. Biological properties of extracellular vesicles and their physiological functions. J Extracell Vesicles 2015;4:27066.

8) Raposo G, Stoorvogel W. Extracellular vesicles: exosomes, microvesicles, and friends. J Cell Biol 2013;200:373-383.

9) Gonzalez E, Falcon-Perez JM. Cell-derived extracellular vesicles as a platform to identify low-invasive disease biomarkers. Expert Rev Mol Diagn 2015;15:907-923.

10) Hirsova P, Ibrahim SH, Verma VK, Morton LA, Shah VH, LaRusso NF, et al. Extracellular vesicles in liver pathobiology: small particles with big impact. Hepatology 2016;64:22192233.

11) Masyuk AI, Huang BQ, Ward CJ, Gradilone SA, Banales JM, Masyuk TV, et al. Biliary exosomes influence cholangiocyte regulatory mechanisms and proliferation through interaction with primary cilia. Am J Physiol Gastrointest Liver Physiol 2010;299: G990-G999.

12) European Association for the Study of the Liver. EASL clinical practice guidelines: management of cholestatic liver diseases. J Hepatol 2009;51:237-267.

13) Edge SB, Compton CC. The American Joint Committee on Cancer: the 7th edition of the AJCC cancer staging manual and the future of TNM. Ann Surg Oncol 2010;17:1471-1474. 
14) Banales JM, Saez E, Uriz M, Sarvide $S$, Urribarri $A D$, Splinter $P$, et al. Up-regulation of microRNA 506 leads to decreased $\mathrm{Cl}^{-}$/ $\mathrm{HCO}_{3}{ }^{-}$anion exchanger 2 expression in biliary epithelium of patients with primary biliary cirrhosis. HEPATOLOGY 2012;56:687-697.

15) Munoz-Garrido P, Marin JJ, Perugorria MJ, Urribarri AD, Erice O, Saez E, et al. Ursodeoxycholic acid inhibits hepatic cystogenesis in experimental models of polycystic liver disease. J Hepatol 2015;63:952-961.

16) Urribarri $\mathrm{AD}$, Munoz-Garrido $P$, Perugorria MJ, Erice $O$, Merino-Azpitarte M, Arbelaiz A, et al. Inhibition of metalloprotease hyperactivity in cystic cholangiocytes halts the development of polycystic liver diseases. Gut 2014;63:1658-1667.

17) Lankisch TO, Metzger J, Negm AA, Vosskuhl K, Schiffer E, Siwy J, et al. Bile proteomic profiles differentiate cholangiocarcinoma from primary sclerosing cholangitis and choledocholithiasis. Hepatology 2011;53:875-884.

18) Li L, Masica D, Ishida M, Tomuleasa C, Umegaki S, Kalloo AN, et al. Human bile contains microRNA-laden extracellular vesicles that can be used for cholangiocarcinoma diagnosis. HEPATOLOGY 2014;60:896-907.

19) Metzger J, Negm AA, Plentz RR, Weismuller TJ, Wedemeyer J, Karlsen TH, et al. Urine proteomic analysis differentiates cholangiocarcinoma from primary sclerosing cholangitis and other benign biliary disorders. Gut 2013;62:122-130.

20) Aebersold R, Mann M. Mass spectrometry-based proteomics. Nature 2003;422:198-207.

21) Domon B, Aebersold R. Mass spectrometry and protein analysis. Science 2006;312:212-217.

22) An T, Qin S, Xu Y, Tang Y, Huang Y, Situ B, et al. Exosomes serve as tumour markers for personalized diagnostics owing to their important role in cancer metastasis. J Extracell Vesicles 2015;4:27522.

23) Burger D, Schock S, Thompson CS, Montezano AC, Hakim AM, Touyz RM. Microparticles: biomarkers and beyond. Clin Sci (Lond) 2013;124:423-441.

24) Azmi AS, Bao B, Sarkar FH. Exosomes in cancer development, metastasis, and drug resistance: a comprehensive review. Cancer Metastasis Rev 2013;32:623-642.

25) Liang B, Zhong L, He Q, Wang S, Pan Z, Wang T, et al. Diagnostic accuracy of serum CA19-9 in patients with cholangiocarcinoma: a systematic review and meta-analysis. Med Sci Monit 2015;21:3555-3563.

26) Levy C, Lymp J, Angulo P, Gores GJ, Larusso N, Lindor KD. The value of serum CA 19-9 in predicting cholangiocarcinomas in patients with primary sclerosing cholangitis. Dig Dis Sci 2005; 50:1734-1740.

27) Kelly SL, Bird TG. The evolution of the use of serum alphafetoprotein in clinical liver cancer surveillance. J Immunobiol 2016;1:1000116.

28) Gerhardt T, Milz S, Schepke M, Feldmann G, Wolff M, Sauerbruch $\mathrm{T}$, et al. C-reactive protein is a prognostic indicator in patients with perihilar cholangiocarcinoma. World J Gastroenterol 2006;12:5495-5500.

29) Lin ZY, Liang ZX, Zhuang PL, Chen JW, Cao Y, Yan LX, et al. Intrahepatic cholangiocarcinoma prognostic determination using pre-operative serum C-reactive protein levels. BMC Cancer 2016;16:792.

30) Saisho T, Okusaka T, Ueno H, Morizane C, Okada S. Prognostic factors in patients with advanced biliary tract cancer receiving chemotherapy. Hepatogastroenterology 2005;52:1654-1658.

31) Colvin H, Mori M. Getting to the heart of the matter in cancer: novel approaches to targeting cancer stem cells. Proc Jpn Acad Ser B Phys Biol Sci 2017;93:146-154.
32) Serizawa N, Tian J, Fukada H, Baghy K, Scott F, Chen X, et al. Galectin 3 regulates HCC cell invasion by RhoA and MLCK activation. Lab Invest 2015;95:1145-1156.

33) Yue X, Ai J, Xu Y, Chen Y, Huang M, Yang X, et al. Polymeric immunoglobulin receptor promotes tumor growth in hepatocellular carcinoma. Hepatology 2017;65:1948-1962.

34) Jiang SS, Weng DS, Wang QI, Pan K, Zhang YJ, Li YQ, et al. Galectin-3 is associated with a poor prognosis in primary hepatocellular carcinoma. J Transl Med 2014;12:273.

35) Haga $H$, Yan IK, Takahashi K, Wood J, Zubair A, Patel T. Tumour cell-derived extracellular vesicles interact with mesenchymal stem cells to modulate the microenvironment and enhance cholangiocarcinoma growth. J Extracell Vesicles 2015;4:24900.

36) Dutta S, Reamtong O, Panvongsa W, Kitdumrongthum S, Janpipatkul K, Sangvanich P, et al. Proteomics profiling of cholangiocarcinoma exosomes: a potential role of oncogenic protein transferring in cancer progression. Biochim Biophys Acta 2015. 1852:1989-1999.

37) Li L, Piontek K, Ishida M, Fausther M, Dranoff JA, Fu R, et al. Extracellular vesicles carry microRNA-195 to intrahepatic cholangiocarcinoma and improve survival in a rat model. HePATOLOGY 2017;65:501-514.

38) Claperon A, Mergey M, Nguyen Ho-Bouldoires TH, Vignjevic D, Wendum D, Chretien Y, et al. EGF/EGFR axis contributes to the progression of cholangiocarcinoma through the induction of an epithelial-mesenchymal transition. J Hepatol 2014;61:325-332.

39) Hoshino A, Costa-Silva B, Shen TL, Rodrigues G, Hashimoto A, Tesic Mark M, et al. Tumour exosome integrins determine organotropic metastasis. Nature 2015;527:329-335.

40) Somoracz A, Tatrai P, Horvath G, Kiss A, Kupcsulik P, Kovalszky I, et al. Agrin immunohistochemistry facilitates the determination of primary versus metastatic origin of liver carcinomas. Hum Pathol 2010;41:1310-1319.

41) Sulpice L, Rayar M, Turlin B, Boucher E, Bellaud P, Desille M, et al. Epithelial cell adhesion molecule is a prognosis marker for intrahepatic cholangiocarcinoma. J Surg Res 2014;192:117-123.

42) Kristiansen TZ, Harsha HC, Gronborg M, Maitra A, Pandey A. Differential membrane proteomics using 18O-labeling to identify biomarkers for cholangiocarcinoma. J Proteome Res 2008;7:4670-4677.

43) Ning S, Guo S, Xie J, Xu Y, Lu X, Chen Y. TROP2 correlates with microvessel density and poor prognosis in hilar cholangiocarcinoma. J Gastrointest Surg 2013;17:360-368.

44) Sasaki M, Matsubara T, Yoneda N, Nomoto K, Tsuneyama K, Sato $\mathrm{Y}$, et al. Overexpression of enhancer of zeste homolog 2 and MUC1 may be related to malignant behaviour in intraductal papillary neoplasm of the bile duct. Histopathology 2013;62:446-457.

45) Tamada S, Shibahara H, Higashi M, Goto M, Batra SK, Imai $\mathrm{K}$, et al. MUC4 is a novel prognostic factor of extrahepatic bile duct carcinoma. Clin Cancer Res 2006;12:4257-4264.

Author names in bold designate shared co-first authorship.

\section{Supporting Information}

Additional Supporting Information may be found at onlinelibrary.wiley.com/doi/10.1002/hep.29291/suppinfo. 